\title{
Three Essays on Investigating Province-Level Carbon Dioxide Emissions in China
}

\author{
Xueting Zhao \\ West Virginia University
}

Follow this and additional works at: https://researchrepository.wvu.edu/etd

\section{Recommended Citation}

Zhao, Xueting, "Three Essays on Investigating Province-Level Carbon Dioxide Emissions in China" (2014). Graduate Theses, Dissertations, and Problem Reports. 117.

https://researchrepository.wvu.edu/etd/117

This Dissertation is protected by copyright and/or related rights. It has been brought to you by the The Research Repository @ WVU with permission from the rights-holder(s). You are free to use this Dissertation in any way that is permitted by the copyright and related rights legislation that applies to your use. For other uses you must obtain permission from the rights-holder(s) directly, unless additional rights are indicated by a Creative Commons license in the record and/ or on the work itself. This Dissertation has been accepted for inclusion in WVU Graduate Theses, Dissertations, and Problem Reports collection by an authorized administrator of The Research Repository @ WVU.

For more information, please contact researchrepository@mail.wvu.edu. 


\title{
Three Essays on Investigating Province-Level \\ Carbon Dioxide Emissions in China
}

\author{
Xueting Zhao \\ Dissertation submitted to the \\ Davis College of Agriculture, Natural Resources and Design \\ at West Virginia University \\ in partial fulfillment of the requirements \\ for the degree of \\ Doctor of Philosophy \\ in \\ Natural Resource Economics \\ Jerald J. Fletcher, Ph.D., Chair \\ J. Wesley Burnett, Ph.D. Co-Advisor \\ Timothy T. Phipps, Ph.D. \\ Alan R. Collins, Ph.D. \\ Stratford M. Douglas, Ph.D. \\ Division of Resource Management \\ Morgantown, West Virginia \\ 2014
}

Keywords: Carbon dioxide emissions, Spatial panel data, Impact factor, Convergence, Forecasting, China

Copyright 2014 Xueting Zhao 


\section{ABSTRACT \\ Three Essays on Investigating Province-Level \\ Carbon Dioxide Emissions in China}

Xueting Zhao

The three essays in this dissertation study the influential factors of energy-related carbon dioxide emission intensity, whether the province-level carbon dioxide emission intensity is convergence, and how spatial panel data models forecast compare with those from non-spatial panel data models for province-level carbon dioxide emissions in China.

The first essay entitled "Spatial Analysis of China Province-Level $\mathrm{CO}_{2}$ Emission Intensity" offers a unique contribution to the literature by investigating the influential factors of energyrelated carbon dioxide emission intensity among a panel of 30 provinces in China covering the period 1990-2010. This study uses novel spatial panel data models to analyze those factors that influence energy-related emission intensity, which are characterized by spatial dependence. It is found that emission intensities are negatively related to per-capita, province-level GDP and population density. This relationship implies that promoting local economic development and population concentration may help to reduce $\mathrm{CO}_{2}$ emission intensity. In addition, emission intensities are positively affected by energy consumption structure and transportation structure. These empirical evidences indicate that Chinese government should encourage the development of less carbon-intensive energy resources and further fuel efficiency standards in its transportation sector. Finally, energy prices have no significant effect on emission intensities. This finding may suggest that the Chinese government should further deregulate energy prices to reduce artificial price distortions.

The second essay entitled "Province-Level Convergence of China $\mathrm{CO}_{2}$ Emission Intensity" further explores the convergence of province-level $\mathrm{CO}_{2}$ emission intensity among a panel of 30 provinces in China over the period 1990-2010. This study use a novel, spatial dynamic panel data model to evaluate an empirically testable hypothesis of convergence among provinces. Based on 
the estimation results, I find evidence that $\mathrm{CO}_{2}$ emission intensities are converging across provinces in China. Moreover, the rate of convergence is higher with the dynamic panel data model (conditional convergence) than with a cross-sectional regression model (absolute convergence). This result suggests that the individual effects that are ignored in cross-sectional regressions potentially create omitted variable bias and the panel data framework arguably offers a more precise (efficiency) rate of convergence. Finally, it is found that province-level $\mathrm{CO}_{2}$ emission intensities are spatially correlated, and the rate of convergence, when controlling for spatial autocorrelation, is higher than with the non-spatial models. This result indicates that technological spillovers, embodied in both the unobserved individual effects and the spatial autocorrelation coefficient, have a direct effect on the rate of convergence of carbon intensity among provinces.

The third essay entitled "Forecasting Province-Level $\mathrm{CO}_{2}$ Emissions in China" examines the performance of spatial panel data models by comparing forecasts of province-level $\mathrm{CO}_{2}$ emissions against empirical reality using dynamic, spatial panel data models with and without fixed effects. From a policy standpoint, understanding how to predict emissions is important for designing climate change mitigation policies. From a statistical standpoint, it is important to test spatial econometrics models to see if they are a valid strategy to describe the underlying data. The results of this essay suggest that the best model of forecasting province-level $\mathrm{CO}_{2}$ emissions is the spatio-temporal panel data model with controlling the fixed effects. The findings demonstrate the importance of considering not only spatial and temporal dependence, but also the heterogeneous characteristics within each province. 


\section{ACKNOWLEDGEMENTS}

I would like to express my sincere appreciation to my advisor, Dr. Jerry Fletcher, for accepting me into the Ph.D. program and funded my graduate education. I am grateful for his staunch support and unending encouragement. I am deeply indebted to my co-advisor and dissertation committee, Dr. Wesley Burnett, for his constant guidance, patient, and willingness to help me achieve this objective. I appreciate all the help, advice, and information I have received from him. I would also thank all my other committee members: Dr. Alan Collins, Dr. Tim Phipps and Dr. Stratford Douglas, for their valuable time reading my dissertation and for their inspiring advices which greatly improved this dissertation. In addition, I would like to thank all the faculty and staff in my department for their constant help and care during my graduate studies at WVU.

My special thanks also goes to my parents and my little brother, for their unconditional love and support during every stage of my life and for always believing in me. I would like to dedicate my thanks to my husband, Song Chen, for his support, encourage and patience inspiring me to do my best and work hard. Most important, I wish to give my heartfelt thanks to my precious daughter, Joanna, for filling my days with sweet smiles and hugs, and being a great cheering section for me.

The usual caveat applies: All remaining errors in this dissertation are my own. ${ }^{1}$

\footnotetext{
1 "This dissertation is partially based upon work supported by the Department of Energy under Award Number DEFC26-06NT42804.

Disclaimer: "This report was prepared as an account of work sponsored by an agency of the United States Government. Neither the United States Government nor any agency thereof, nor any of their employees, makes any warranty, express or implied, or assumes any legal liability or responsibility for the accuracy, completeness, or usefulness of any information, apparatus, product, or process disclosed, or represents that its use would not infringe privately owned rights. Reference herein to any specific commercial product, process, or service by trade name, trademark, manufacturer, or otherwise does not necessarily constitute or imply its endorsement, recommendation, or favoring by the United States Government or any agency thereof. The views and opinions of authors expressed herein do not necessarily state or reflect those of the United States Government or any agency thereof."
} 


\section{TABLE OF CONTENT}

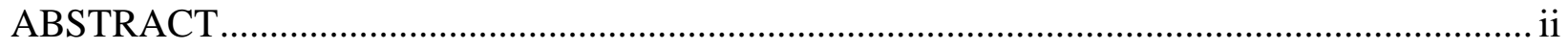

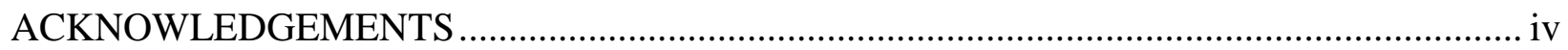

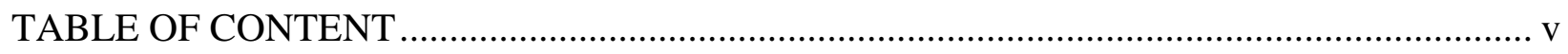

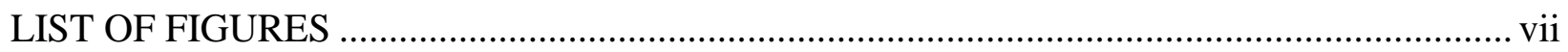

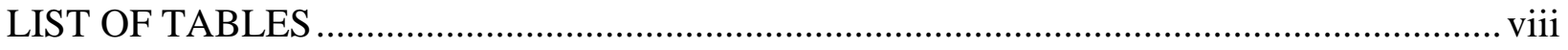

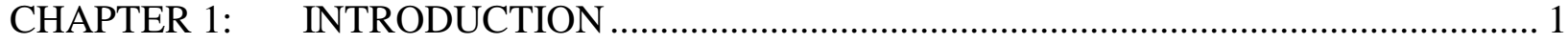

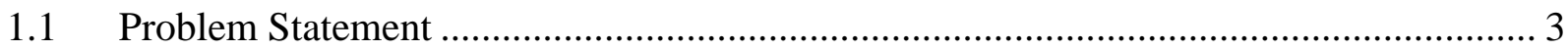

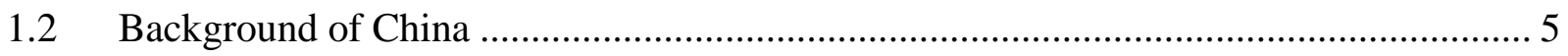

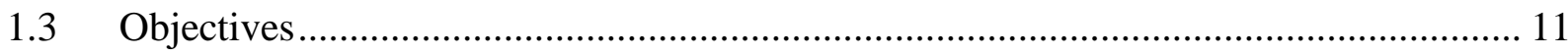

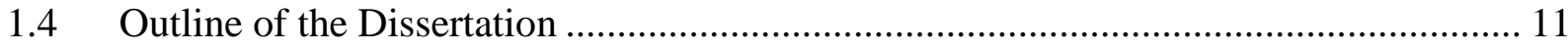

CHAPTER 2: $\quad$ BACKGOUND AND LITERATURE REVIEW ...................................... 12

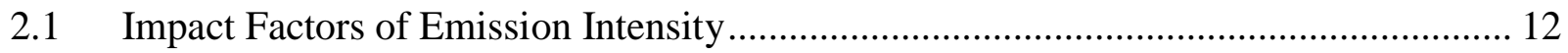

2.2 Development of Beta Convergence................................................................... 13

2.3 Development of Spatial Econometric Models ......................................................... 16

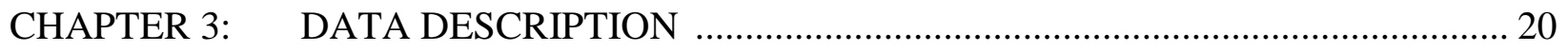

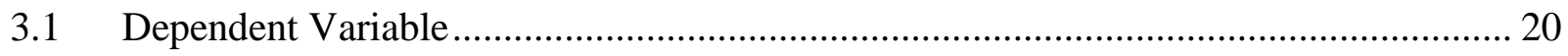

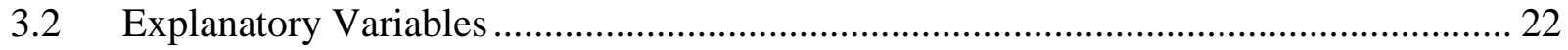

CHAPTER 4: $\quad$ SPATIAL ECONOMETRIC TECHNIQUES .......................................... 26

4.1 Spatial Autoregressive Model (SAR) / Spatial Lag Model (SLM) ........................... 26

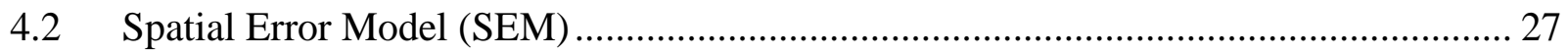

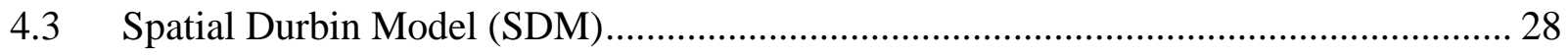

4.4 Spatial Dynamic Panel Data Model (SDPD) …...................................................... 29

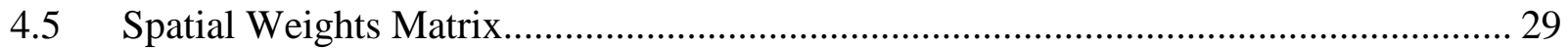

CHAPTER 5: $\quad$ SPATIAL ANALYSIS OF CHINA PROVINCE LEVEL CO $\mathrm{CO}_{2}$ EMISSION

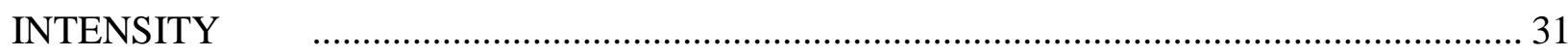

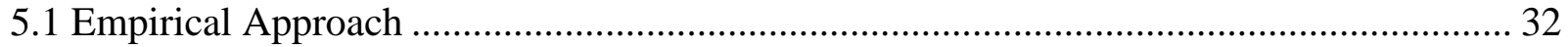

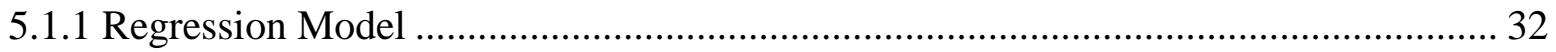

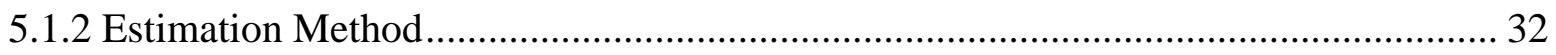




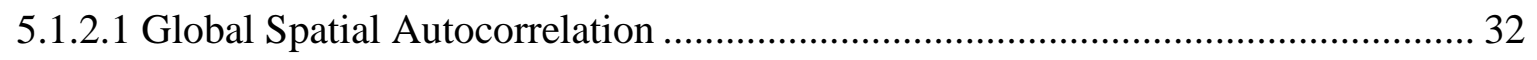

5.1.2.2 Spatial Econometric Analysis ......................................................................... 33

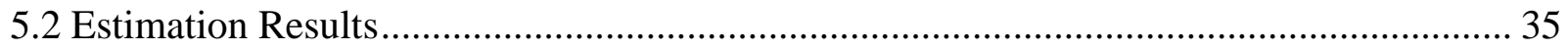

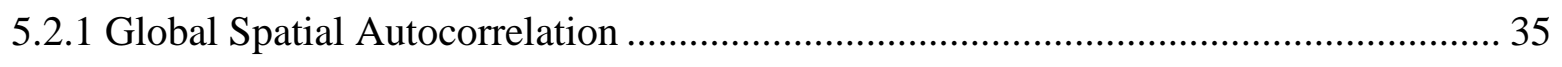

5.2.2 Empirical Results of Spatial Econometric Models .................................................. 38

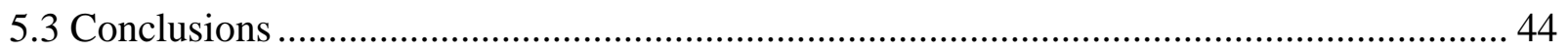

CHAPTER 6: PROVINCE LEVEL CONVERGENCE OF CHINA $\mathrm{CO}_{2}$ EMISSION $^{-}$

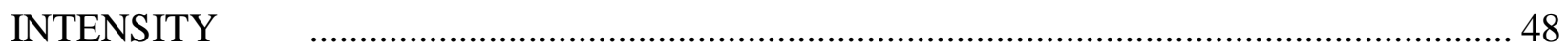

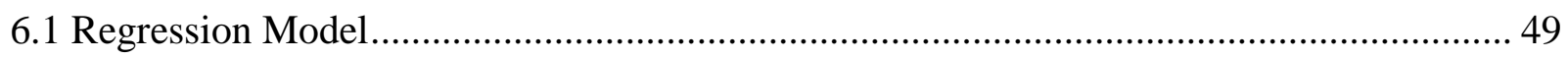

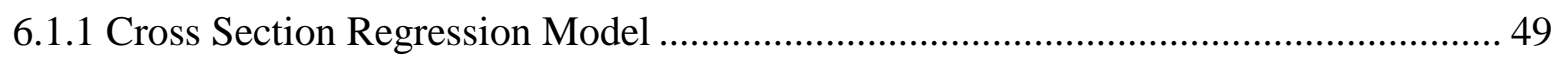

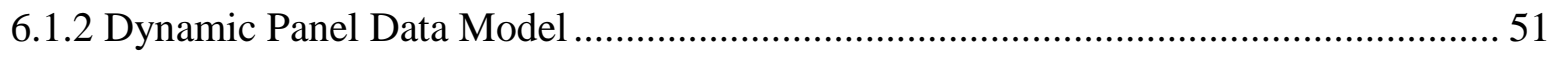

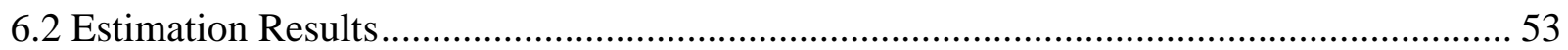

6.2.1 Empirical Results Using Cross Sections ................................................................. 53

6.2.2 Empirical Results Using Dynamic Panel Data ........................................................... 58

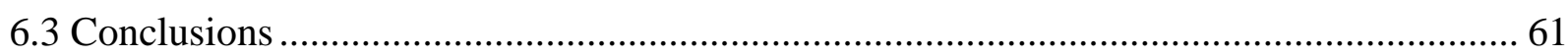

CHAPTER 7: FORECASTING PROVINCE LEVEL CO $\mathrm{CO}_{2}$ EMISSIONS IN CHINA ........... 63

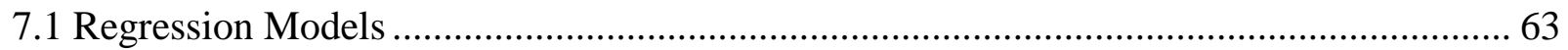

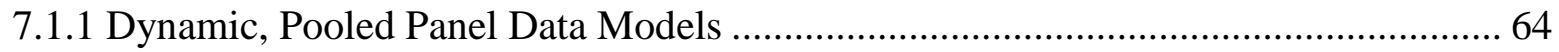

7.1.2 Dynamic Panel Data Models with Fixed/Random Effects ............................................ 65

7.1.2.1 Dynamic Fixed Effects Panel Data Models ............................................................ 66

7.1.2.2 Dynamic Random Effects Panel Data Models...................................................... 67

7.2 Forecast Performance of the Different Models ………………...................................... 68

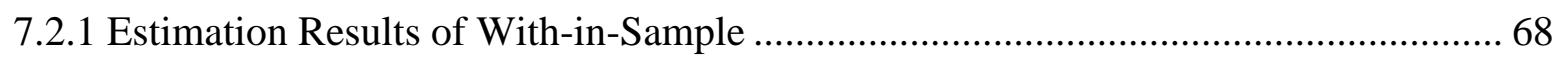

7.2.2 Forecasting Performance ………………………................................................. 72

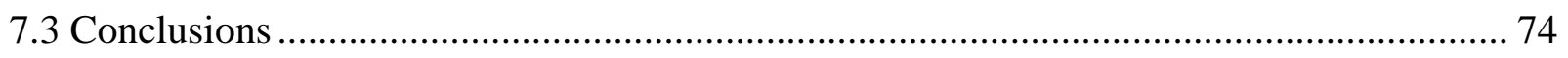

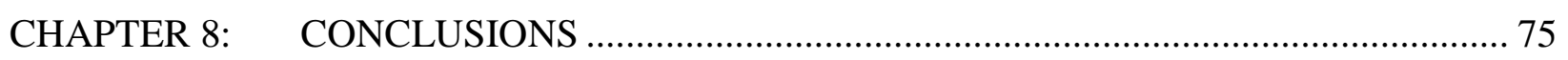

8.1 Policy Implications ........................................................................................................ 77

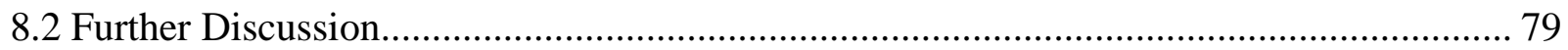

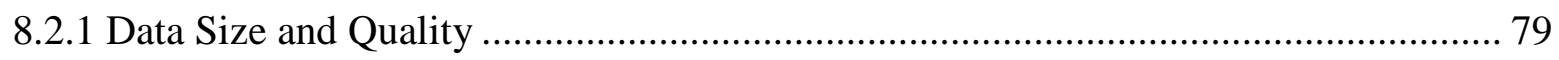

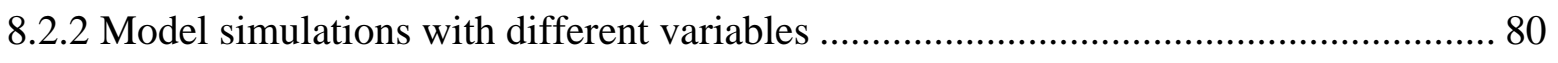

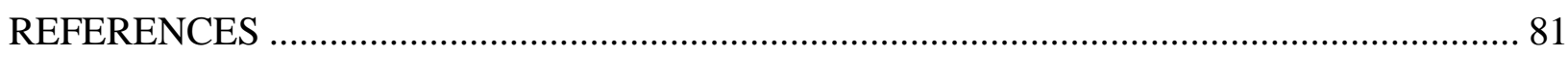




\section{LIST OF FIGURES}

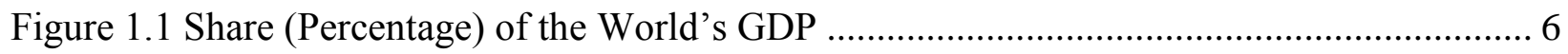

Figure 1.2 Share (Percentage) of the World's Energy Consumption ......................................... 7

Figure 1.3 Share (Percentage) of the World's $\mathrm{CO}_{2}$ Emissions ................................................. 7

Figure 1.4 Provincial $\mathrm{CO}_{2}$ emission intensity through time …............................................... 8

Figure 1.5 Spatial distribution of average $\mathrm{CO}_{2}$ emission intensity over the sample period ........... 9

Figure $1.6 \mathrm{CO}_{2}$ emission intensity of China, 1990-2010 _...................................................... 10

Figure 2.1 CO $\mathrm{CO}_{2}$ emission intensity of each province in China, 1990-2010................................... 14

Figure 5.1 Moran Scatterplot of China's Provincial CO 2 Emission Intensity (1990-2010) .......... 37 


\section{LIST OF TABLES}

Table 3.1 Carbon Emission Coefficients for Various Types of Energy ................................... 22

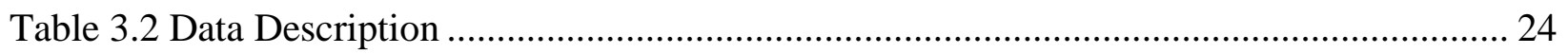

Table 5.1 Moran's I Index of China's $\mathrm{CO}_{2}$ Emission Intensity ............................................. 35

Table 5.2 Estimation results of non-spatial panel data models ............................................ 39

Table 5.3 Post diagnostic tests of joint significance of fixed effects ..................................... 40

Table 5.4 Estimation results of spatial panel data models and interaction effects .................... 40

Table 5.5 Post diagnostic tests of spatial specification .................................................. 41

Table 5.6 Direct \& Indirect effects of SDM model ...................................................... 43

Table 6.1. Cross-Sectional Regression without Spatial Effects........................................... 54

Table 6.2. Cross-Sectional Regression with Contemporary Spatial Effects ............................ 56

Table 6.3. Cross-Sectional Regression with Contemporary Spatial Effects and Lagged Spatial

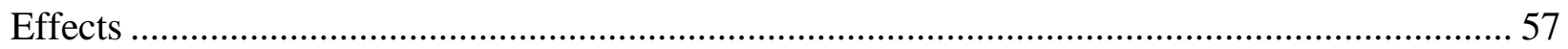

Table 6.4. Dynamic Panel without Spatial Effects ............................................................ 58

Table 6.5. Dynamic Panel with Contemporary Spatial Effects ............................................. 59

Table 6.6. Dynamic Panel with Contemporary Spatial Effects and Lagged Spatial Effects ....... 59

Table 7.1 Estimation Results of the Dynamic Pooled Panel Data Models ................................. 69

Table 7.2 Estimation Results of the Dynamic Fixed Effect Panel Data Models ....................... 70

Table 7.3 Estimation Results of the Dynamic Random Effects Panel Data Models .................. 71 
Table 7.4 LM test results of the different dynamic panel data models .................................. 72

Table 7.5 Forecast Error Performance of the different dynamic panel data models .................. 73 


\section{CHAPTER 1: INTRODUCTION}

There is a strong consensus that climate change poses one of the most serious challenges to future economic and social development throughout the world. In recent years, with an increasing frequency of disastrous weather, the impacts of climate change and greenhouse gases (GHG) have received more attention, and these issues have become more serious and far-reaching than previously thought. There is a growing conviction that the main reason for undesirable changes in the global climate is the increasing accumulation of GHG in the atmosphere. The Fifth Assessment Report published by the Intergovernmental Panel on Climate Change (IPCC) in 2013 notes that global GHG emissions contributed a global mean surface warming likely to be in the range of $0.5^{\circ} \mathrm{C}$ to $1.3^{\circ} \mathrm{C}$ over the period 1951 to 2010 . The report further stresses that carbon dioxide $\left(\mathrm{CO}_{2}\right)$ is the most important anthropogenic $\mathrm{GHG}$, and that the global atmospheric concentration of $\mathrm{CO}_{2}$ now substantially exceed the highest concentrations recorded in ice cores during the past 800,000 years (IPCC,2013).

Humanity's coordinated policy response to this problem is the United Nations' climate negotiation process. In June 1992, the United Nations Framework Convention on Climate Change (UNFCCC) was signed at the United Nations Conference on Environment and Development (UNCED) in Rio de Janeiro by more than 150 countries to promote international cooperation for achieving GHG reductions. It provided a political framework in which climate change themes can be addressed.

The most important milestone of the negotiation process so far is the "Kyoto Protocol" which was signed in 1997. The purpose of the Kyoto Protocol was to restrict GHG emissions in developed countries. Under the Protocol, Annex I countries (37 industrialized countries and the 
European community) committed themselves to cutting their aggregate anthropogenic $\mathrm{CO}_{2}$ equivalent emissions by at least 5\% below 1990 levels by 2008 to 2012. According to the Protocol, undeveloped nations are not required to reduce their emissions whatsoever. China, as one of the developing countries, is not Annex I country and therefore is not obligated to reduce emissions. Despite some attractive design elements, the Kyoto Protocol alone is unlikely to have a significant impact on global GHG emissions.

With the "Copenhagen Accord Submission", which reached in 2009, countries representing over $80 \%$ of global emissions have submitted emissions reduction targets. As the largest developing country and the largest $\mathrm{CO}_{2}$ producer ${ }^{2}$, China is switching roles from an undeniable victim to an increasingly dominant contributor with its rapidly increasing emissions. As such China faces pressure to take a more proactive position in negotiations in order to not to lose credibility in the international community. In the agreement, China set the goal to reduce its carbon intensity ${ }^{3}$ by $40-45 \%$ of 2005 levels by 2020 . China also promised to increase the share of non-fossil fuels in primary energy consumption to around $15 \%$ by 2020 .

The Cancun agreements reached on December 11 at the 2010 United Nations Climate Change Conference, represent key steps in plans to reduce GHG emissions and to help developing nations protect themselves from climate impacts and build sustainable futures. China and the U.S., the world's two largest emitters of GHG emissions, played key roles in the Cancun agreement. One of the main objectives of the agreement is to encourage the participation of all countries, not only the developed countries, but also the developing counties, in reducing these emissions, in

\footnotetext{
${ }^{2}$ According to a recent report released by the Netherlands Environmental Assessment Agency, China surpassed the US to become the largest aggregate emitter of $\mathrm{CO}_{2}$ emissions in 2006.

This report can be accessed online at:

http://www.pbl.nl/en/dossiers/Climatechange/moreinfo/ChinanownolinCO2emissionsUSAinsecondposition

${ }^{3}$ Carbon intensity is defined as the units of $\mathrm{CO}_{2}$ emissions per unit Gross Domestic Product $\left(\mathrm{CO}_{2}\right.$ emissions divided by GDP).
} 
accordance with each country's different responsibilities and capabilities. In a mutually accountable way, these agreements formed the basis for the largest collective effort the world has ever seen to reduce emissions with national plans captured formally at an international level.

\subsection{Problem Statement}

In the common sense, the geographic distribution of $\mathrm{CO}_{2}$ emissions does not affect the global climate impact. That is, no matter where emissions original, climate change is a global issue. However, the distribution of the sources of emissions is important for policy formulation at the international, national, and ultimately, at the local level. It does also affects the political economy of negotiating multilateral agreements (Aldy, 2006). Combating global climate change will require multilateral, international agreements, which will require long negotiation process, and will be very hard to achieve. But the fight against local climate change causes can easily start at home. That is, mitigation policies will likely come at the expense of economic growth among regions. So, understanding the distribution of carbon dioxide emissions $\left(\mathrm{CO}_{2}\right)$ through time and space can support the development of appropriate regulatory frameworks to mitigate harmful anthropogenic GHG emissions.

With the support of the worldwide organizations, a number of developed countries have committed to reduce domestic $\mathrm{CO}_{2}$ emissions. More and more developing countries have begun to be involved in this worldwide movement, including China. As the $\mathrm{No}_{1} \mathrm{CO}_{2}$ producer in the world, China's participation is very important. If China were to formulate a national climate change policy or agree to ratify an international agreement, such as the Cancun Agreement, then it must begin to look inward to determine the major sources and distribution of emissions in addition to determining how to reduce these emissions. Within this look inward, policy makers 
may be interested in determining how the distribution of province-level emission intensity is changing over time. According to Herrerias (2012), convergence in energy intensity could imply that technological differences across regions diminish over time. That is, do interregional differences in technology tend to disappear or increase over time? If the differences diminish over time, it implies the economy has the ability to make the environment cleaner, then policymakers may be less worried about the mitigation scheme. If, on the other hand, the differences tend to perpetuate over time, it implies a lack of diffusion of energy-related technologies, thus making it difficult to reach the mitigation targets. In this case, policymakers may want to encourage knowledge diffusion by providing technological policies.

In neoclassical growth theory, economies are assumed to be independent; however, technological advances, labor and capital, and environmental policies in one economy might be transmitted to other economies. Ignoring spatial autocorrelation may lead to unreliable statistical inference if the spatial effect is present but omitted. The motivation for the idea of spatial spillovers is related to the concept of economic distance, which suggests that the closer two regions are to one another in geographic distance, the more likely that their economy's will be inter dependent (Conley and Ligon, 2002). In the case of mitigation policy, spatial spillovers indicate that policies adopted in one region will affect policies in neighboring regions, which implies that regions may strategically interact to balance mitigation and economic policy goals. A line of research within the urban economics and regional science literature explores this type of strategic interaction among jurisdictions by explicitly modeling how one jurisdiction's policies affect neighboring policies and vice versa (see (Brueckner, 2003) for a review).

Despite advances in spatial econometric models, they have come under criticism for problems associated with identification and for a lack of appeal to theoretical foundations 
(Partridge et al., 2012). The problem of identification is similar to Manski's (1993) "reflection problem," where group average characteristics (neighboring province carbon dioxide emissions and structural characteristics) affect individual outcomes (local carbon dioxide emissions) but the parameters in the model are not identifiable. These criticisms are very important, however, addition research is needed on causality based upon correct model specification and/or the correct interpretation of parameter estimates. To further test the validity of spatial panel data models, an alternative validation strategy that is less dependent on prior theory will be used in this dissertation. That is, these models will be taken as black box and be tested against empirical reality (Freedman, 1991).

\subsection{Background of China}

Since the market-oriented reform of 1978, China has experienced remarkable economic growth at an average annual growth rate of 9.8\%. Its GDP has reached 40,120.20 billion Chinese Yuan (CNY) (about $\$ 5,815$ billion) by the end of 2010 and ranked 2 nd in the world following the US (Data from the World Bank). Figure 1.1 displays the share of the world's GDP of China, USA, India and OECD without USA during the period from 1990 to 2010. It is clear that China's GDP has rapidly increased; the share of the world's GDP has risen from $1.63 \%$ to $9.37 \%$ in the last twenty years. 


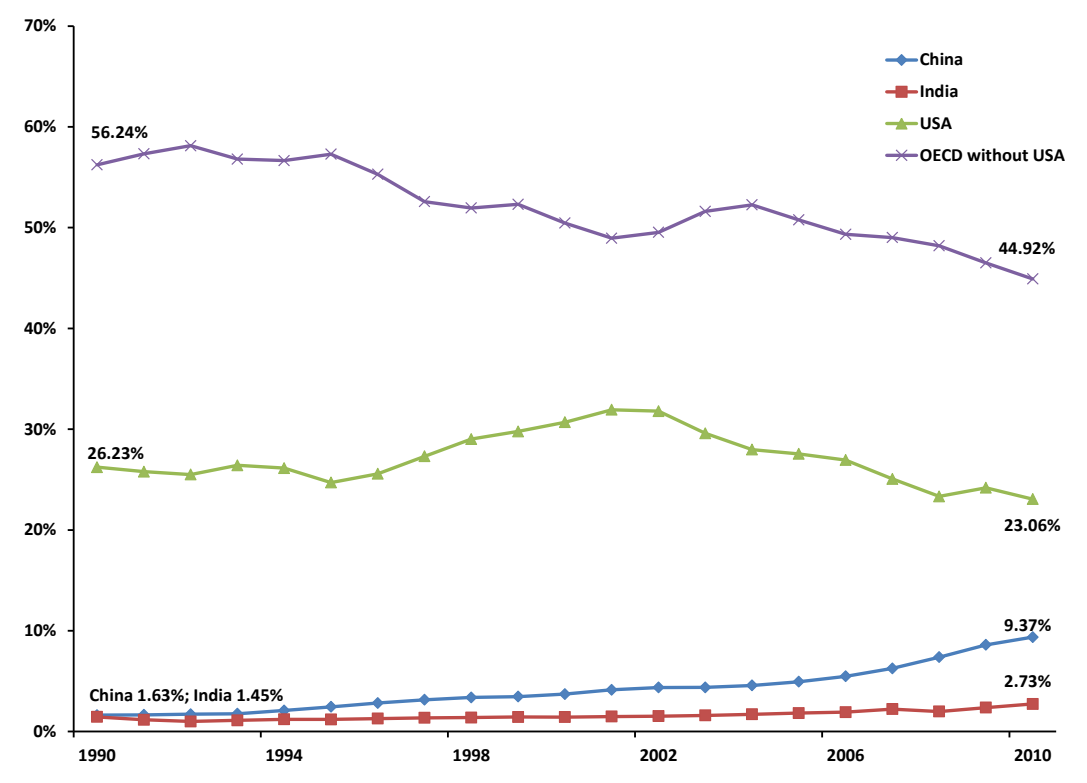

Figure 1.1 Share (Percentage) of the World's GDP

However, this rapid economic growth is based on high energy consumption and high GHG emissions. More than 30 years of rapid industrialization has burned substantial amounts of coal for energy and thereby produced large increases in GHG emissions. China's energy consumption has increased from 0.99 billion tce (tons of standard coal equivalent) in 1990 to 3.25 billion tce in 2010, at an average annual increase rate of 5.84\% (Data from China Statistical Yearbook). Figure 1.2 shows that China's energy consumption as a proportion of the world total grew from $10.06 \%$ in 1990 to $19.15 \%$ in 2010 , nearly doubled in twenty years. Figure 1.3 displays the share of the world's $\mathrm{CO}_{2}$ emissions. China's $\mathrm{CO}_{2}$ emissions accounted for $11.03 \%$ in 1990 and increased to $21.92 \%$ in 2010 of the world's total, with an average annual growth rate of $6.57 \%$. 


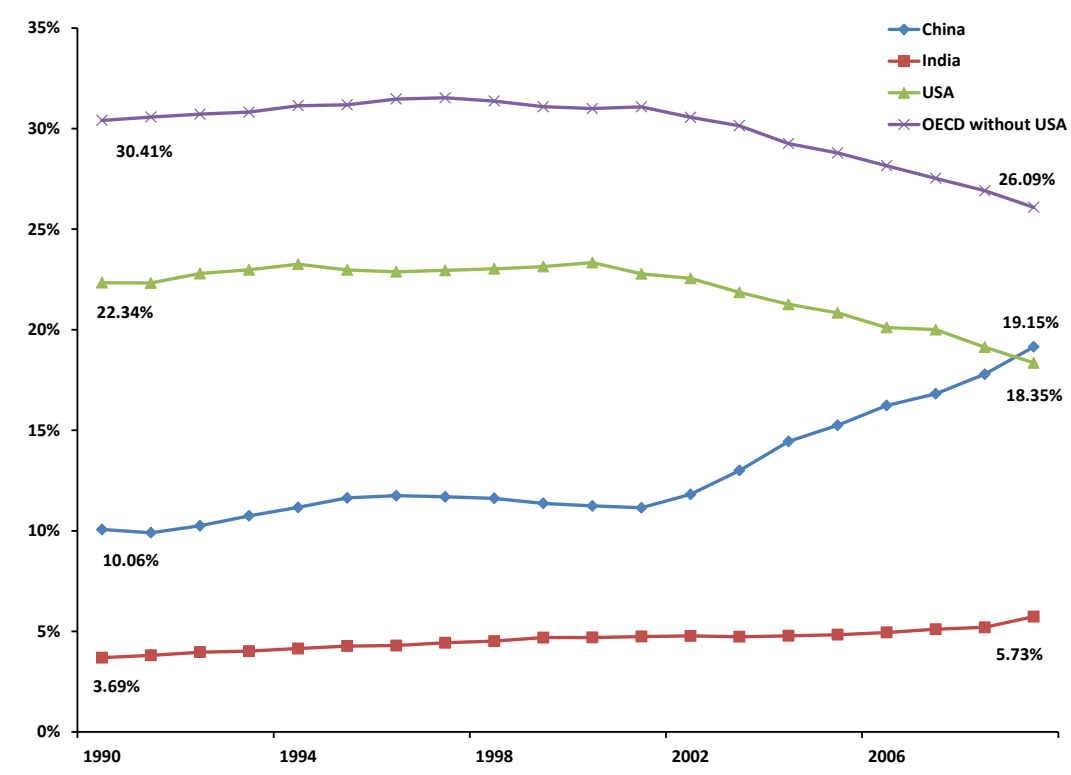

Figure 1.2 Share (Percentage) of the World's Energy Consumption

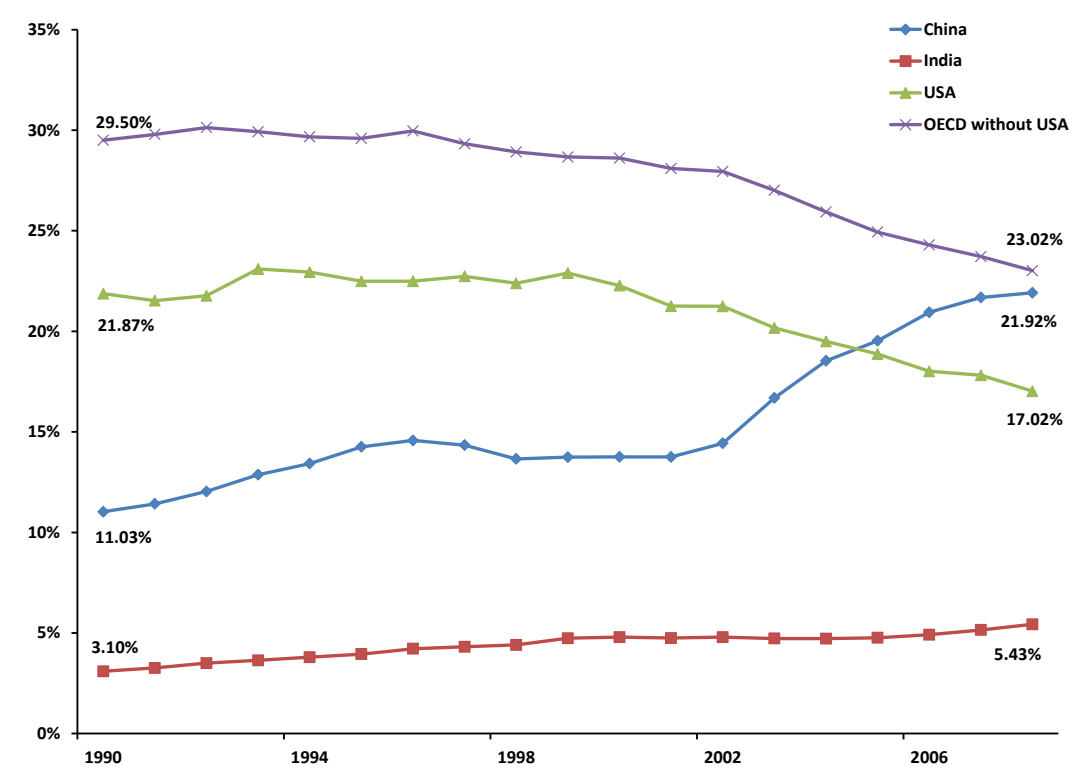

Figure 1.3 Share (Percentage) of the World's $\mathrm{CO}_{2}$ Emissions

An analysis at a more disaggregated level reveals an imbalance in economic growth and energy consumption among different provinces in China. For example in 2010, Jiangsu, Shandong, 
and Guangdong provinces accounted for over 3 trillion CNY in GDP whereas provinces such as Hainan, Qinghai, and Ningxia accounted for less than 300 billion CNY. These disparities also reveal themselves in terms of province-level $\mathrm{CO}_{2}$ emissions.

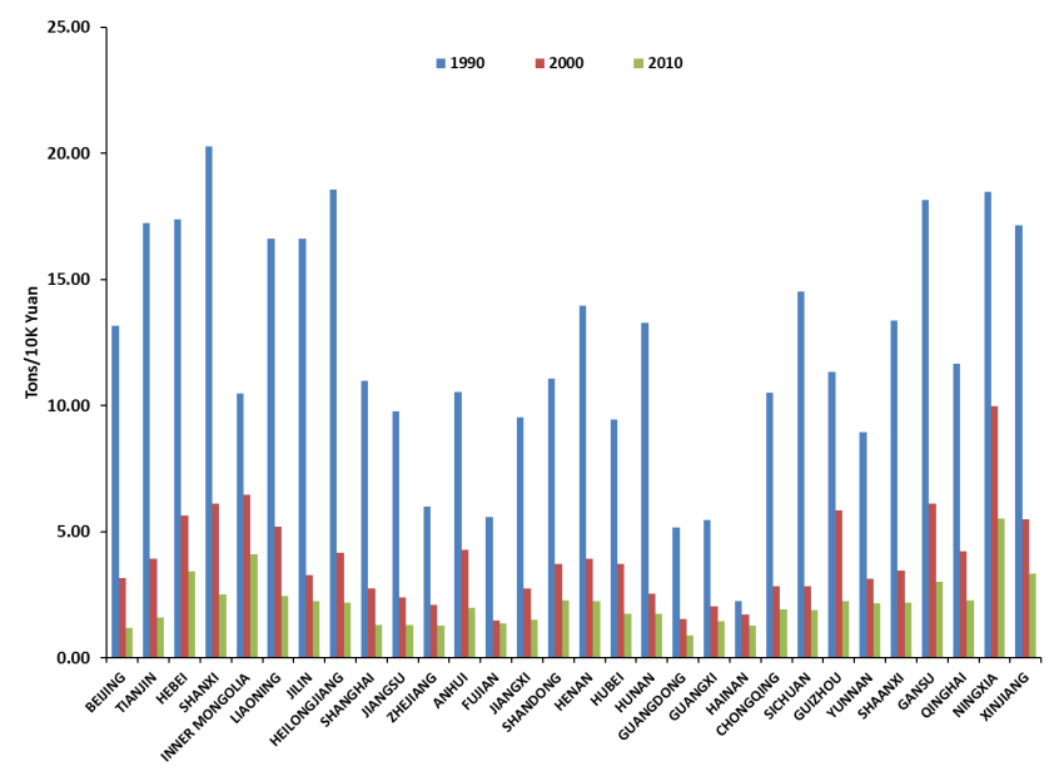

Figure 1.4 Provincial $\mathrm{CO}_{2}$ emission intensity through time

Three points in time $\left(1990,2000\right.$, and 2010) are chosen to display China's provincial $\mathrm{CO}_{2}$ emission intensity distribution, which are shown in Figure 1.4. From 1990 to 2010, the $\mathrm{CO}_{2}$ emission intensity of each province decreased year by year. The results show that provinces such as Shanxi and Ningxia consistently have the highest $\mathrm{CO}_{2}$ emission intensities - their $\mathrm{CO}_{2}$ emission intensities are almost six times higher that provinces such as Hainan and Guangdong. That means, in order to produce the same GDP, the provinces with the highest $\mathrm{CO}_{2}$ emission intensity will produce about six times the $\mathrm{CO}_{2}$ emissions as the provinces with the lowest $\mathrm{CO}_{2}$ emission intensity. The disparity of $\mathrm{CO}_{2}$ emission intensity reveals itself in trends of spatial clustering. As displayed in Figure 1.5, the northern and western provinces are aggregated in terms 
of their higher $\mathrm{CO}_{2}$ emission intensities, and the southern and eastern provinces are generally aggregated in terms of their low $\mathrm{CO}_{2}$ emission intensities.

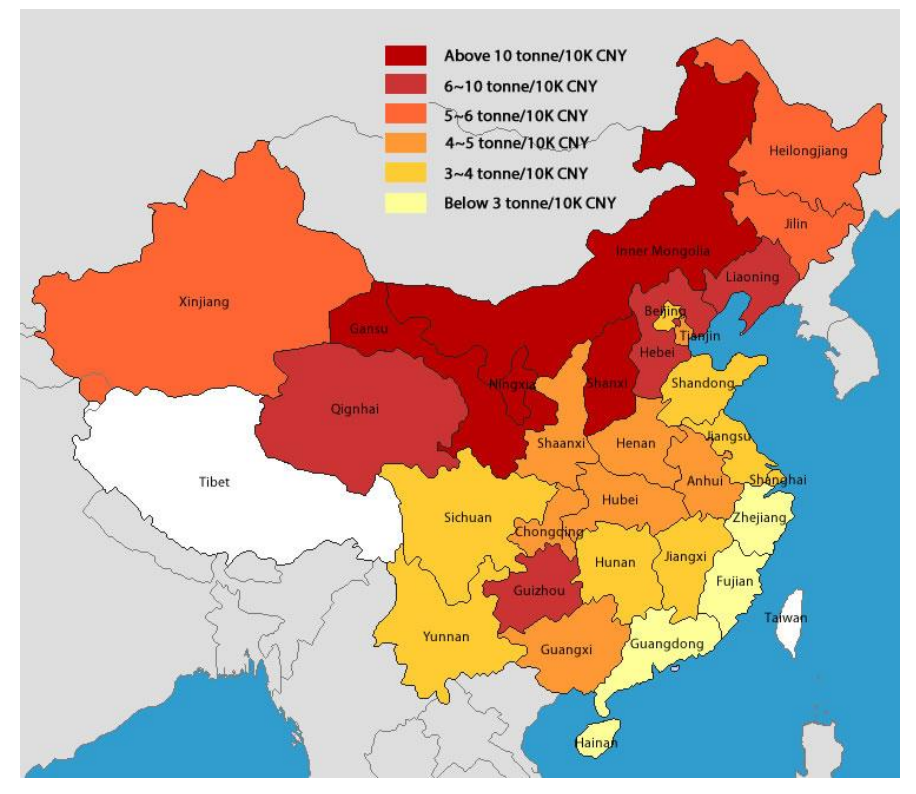

Figure 1.5 Spatial distribution of average $\mathrm{CO}_{2}$ emission intensity over the sample period

These differences have caused the government to change the economic growth pattern so as to realize the economic, energy and environment coordinated sustainable development. Three levels of policies have been formulated by the Chinese government in the outline of the "Twelfth Five-Year Plan for National Economic \& Social Development of the People's Republic of China". The national level plan is to slow down the rate of economic growth. The "Twelfth Five-Year Plan (2011-2015)" proposed that the economic growth target is to significantly improve the quality and efficiency of energy use based on an average annual growth rate of $7 \%$, much lower than in the previous 20 years (The average annual growth rate was $15.74 \%$ between 1990 and 2010). The regional level plan is to promote balanced economic development across all regions. In the planning of national development priority zones, the land space is divided into optimized development, key development, restricted development and prohibited development areas 
according to resources, environmental carrying capacity, existing development and so on, to coordinate future regional development. On the industrial level, policies such as clean energy, renewable energy development, energy saving and emission reductions, etc. have been formulated. Among them, the $\mathrm{CO}_{2}$ emission controlling policies are most important parts.

With the "Copenhagen Accord Submission," China set the goal to reduce its carbon intensity by $40-45 \%$ of 2005 levels by 2020. Although $\mathrm{CO}_{2}$ emission intensities have been decreasing year by year in China as illustrated in Figure 1.6, the country still has a long way to go to achieve its reduction goal. These reductions are expected to be achieved through improvements in energy efficiency, and reductions in energy consumption.

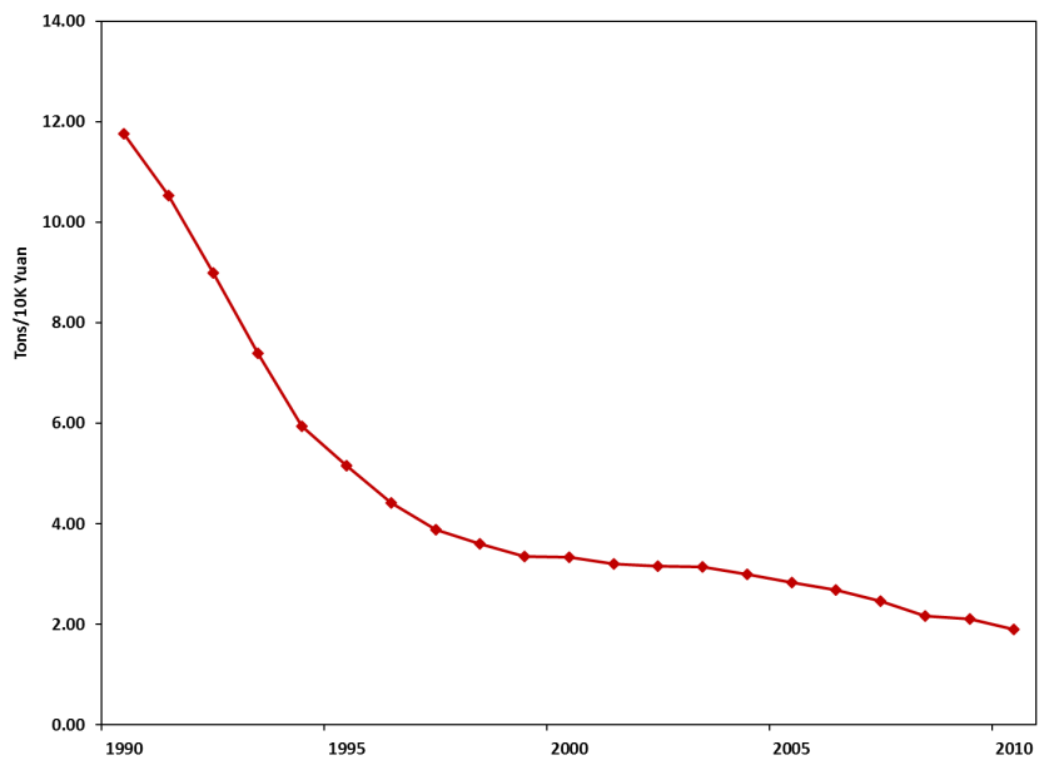

Figure 1.6 $\mathrm{CO}_{2}$ emission intensity of China, 1990-2010 


\subsection{Objectives}

The overall objective of this research is to conduct a spatial panel data empirical analysis of China's province level carbon dioxide emissions, so that to provide a basic reference for policy makers to set emission reduction targets and policy.

The specific objectives are to:

- Analyze the driving forces of China's province level $\mathrm{CO}_{2}$ emission intensity by comparing the non-spatial model and the different spatial econometric models.

- Estimate the province level spatial convergence of $\mathrm{CO}_{2}$ emission intensity in China.

- Test the empirical application of spatial econometric models by comparing the forecasting emissions and the reality emissions.

\subsection{Outline of the Dissertation}

The dissertation consists of eight chapters including the introduction. Chapter 2 offers the literature review. Chapter 3 offers a description of the data types and sources. Chapter 4 gives a brief introduction to spatial econometric techniques. Chapter 5 presents the first essay that studies the influential factors of energy-related carbon dioxide emission intensity in China. Chapter 6 presents the second essay that examines whether the province-level carbon dioxide emission intensity is convergence in China. Chapter 7 presents the third essay that provides an empirical analysis of how the spatial panel data models perform in forecasting against non-spatial panel data models for province-level carbon dioxide emissions in China. This dissertation concludes in Chapter 8, with the main directions of future research. 


\section{CHAPTER 2: BACKGOUND AND LITERATURE REVIEW}

\subsection{Impact Factors of Emission Intensity}

This estimate of $\mathrm{CO}_{2}$ emissions, based on energy consumption, is frequently used as proxy for actual emissions since carbon dioxide emissions are highly related to energy consumption (Blasing et al., 2004). This estimate of emissions is consistent with emission estimates found within such sources as the International Energy Agency, the U.S. Energy Information Administration, the British Petroleum Statistical Review of World Energy, the World Bank, and the United Nations (BP, 2012; IEA, 2012; UN, 2012; USEIA, 2012; WB, 2012). Since carbon dioxide emissions are based on estimates of energy consumption, it also represented as "energyrelated" emissions. The reason that these energy-related estimates are used is because it would be too costly to monitor such a large variety of mobile and stationary sources of emissions (Auffhammer and Steinhauser, 2007). The distinction between actual versus estimated emissions is important however, because I are not making the claim that there are spillovers in $\mathrm{CO}_{2}$ emissions themselves rather, there are province-level spillovers in energy consumption which in turn create $\mathrm{CO}_{2}$ emissions. More specifically, I argue that there is spatial dependence among the drivers of energy-related emissions and other economic forces which cross provinces. Therefore, factors that influence energy intensity also influence $\mathrm{CO}_{2}$ emission intensity.

Past studies have found that the main factors driving China's environmental emissions are pressures from population, urbanization, industrialization, GDP per capita and energy intensity (Kambara, 1992; Fan et al., 2006; Hang and Tu, 2007; Ma and Stern, 2008; Halicioglu, 2009; Lin et al., 2009; Li et al., 2011). These factors have a positive effect on emissions but the impact has been gradually declining over the past few decades. Using a decomposition analysis (similar to the 
Kaya identity), Fan et al. (2006) found that GDP, energy use, and population have the greatest impact on $\mathrm{CO}_{2}$ emissions in China from 1975-2000. Using a bounds testing procedure of cointegration, Halicioglu (2009) found that carbon dioxide emissions are determined by energy consumption, income and foreign trade in the long-run relationship. Other factors such as technological advancement have also been identified as influencing China's $\mathrm{CO}_{2}$ emissions.

Despite China's high (aggregate) carbon dioxide emissions, the country has experienced an overall decrease in energy intensity since the 1980s due to adjustments in the industrial sector (Kambara, 1992). Ma and Stern (2008) found that structural changes at the industrial and sectoral level are the main factors driving the decline of China's overall energy intensity for the period 1980-2003. In addition to structural changes, Hang and Tu (2007) found that energy prices have played an important role in the improvement of China's energy efficiency, which in turn has put less pressure on the country's energy intensity.

\subsection{Development of Beta Convergence}

The concept of convergence comes from economic growth literature. In the most general sense, it refers to a decrease in the differences of the economic growth across countries or regions over time. However, convergence is not restricted to the economic growth literature alone, and has been applied recently to other fields, including energy economics (Ezcurra, 2007; Duro et al., 2010; Ma and Oxley, 2012; Herrerias, 2012; Herrerias and Liu, 2013). According to Islam (2003), there are different definitions of convergence that are in turn linked to econometric approach in different ways. Among them, we can distinguish between absolute convergence and conditional convergence. The absolute convergence means if economies are identical in terms of preferences and technology, with time they tend to reach the same steady state level (Solow, 1956). The 
conditional convergence means convergence after differences in the steady states across countries have been controlled for (Islam, 1995).

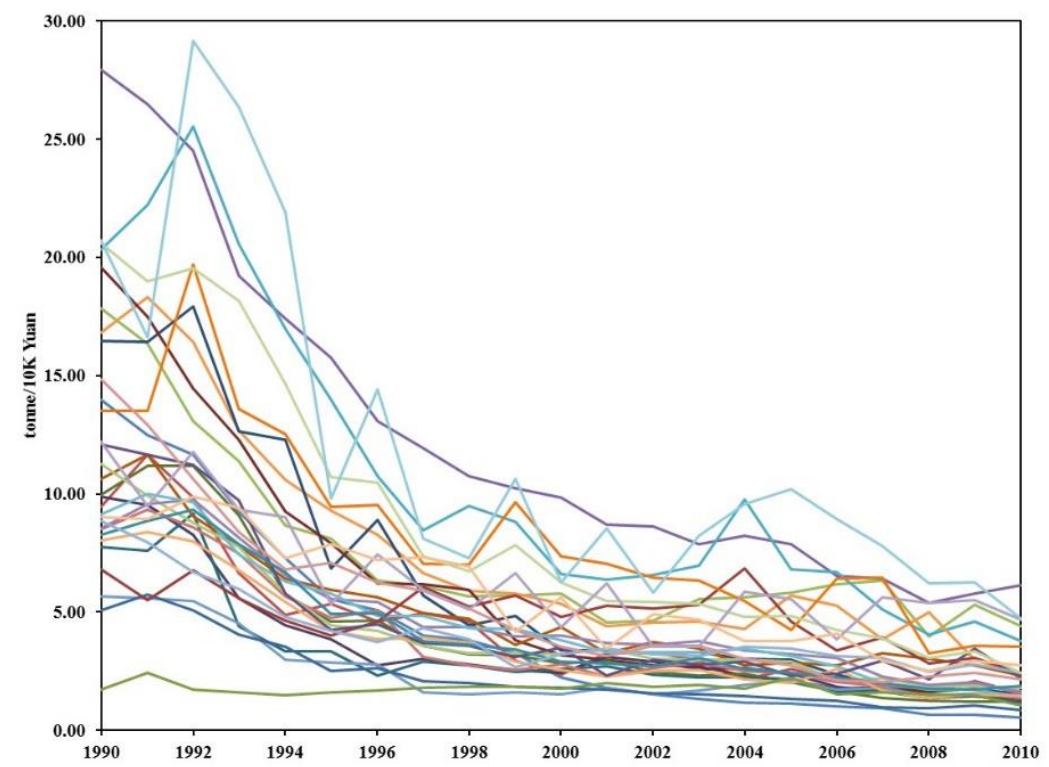

Figure 2.1 $\mathrm{CO}_{2}$ emission intensity of each province in China, 1990-2010

In the last two decades, the carbon dioxide emission intensities across the provinces in China have been decreasing year by year as illustrated in Figure 2.1. A large number of past studies have examined the factors which have led to the decline in $\mathrm{CO}_{2}$ emission intensity. For example, Liddle (2010) found that improvements in technology, changes in the country's economic structure, and energy efficiency accounted for most of the decline. Zhao et al. (2014) found that improvements in energy consumption structure, transportation structure and the aggregation of population could reduce the $\mathrm{CO}_{2}$ emission intensity in China. Others have found that an adjustment in economic structure and a decline in the secondary industry's $\mathrm{CO}_{2}$ emission intensity have reduced China's $\mathrm{CO}_{2}$ emission intensity (Gonzalez and Martinez, 2012; Ma et al., 2012; Ma and Oxley, 2012). However, an examination as to whether the differences in China's province-level 
$\mathrm{CO}_{2}$ emission intensities have diminished over time, resulting in convergence, has received little attention in the literature.

There are two types models generally used to estimate $\beta$-convergence in the literature: cross-sectional models (Fan and Casetti, 1994; Rey and Montouri, 1999; Ezcurra et al., 2007) and panel data models (Islam, 1995; Lopez-Rodriguez, 2008). The traditional neoclassical crosssectional regression model assumes that all regions or economies under consideration have the same steady state income path. Islam (1995) proposed a panel data approach to study growth convergence. The motivation for the panel data approach is to capture the differences across regions or countries. The unobserved differences such as preferences and technology are not easily measurable, so they can be treated as unobserved individual effects in the panel data regression framework (Hsiao, 2002).

However, most of these approaches typically ignore spatial autocorrelation within the underlying data. Spatial autocorrelation can be an important factor in determining regional convergence. To wit, regional scientists often posit that the rates of economic growth are interdependent across regions due to (economic) spillover effects (Conley and Ligon, 2002). Therefore, a spatial, dynamic panel data framework would seem to be appropriate because it controls for both time-invariant heterogeneity across regions and spatial autocorrelation between regions. The preponderance of empirical evidence on regional $\beta$-convergence is based almost exclusively on cross-sectional or panel data models without spatial effects. Arguably, regional data cannot be regarded as spatially independent because of the presence of similarities among neighboring regions. As a result, models without spatial effects may lead to biased or inefficient estimates of the rate of convergence (Arbia et al., 2005). Further, if the growth rates of the poor regions are higher than the growth rates of the rich regions, the spatial inequality may decrease 
over time, which may result in convergence (Gezici and Hewings, 2007). Even though the neoclassical economic model assumes perfect mobility of factors of production between economies, there may be significant adjustment costs or barriers to mobility for labor and capital. In cases where regions pursue their own growth promoting policies, there may be spillover effects from those regions to the adjacent regions (Anselin, 1998). Thus, incorporating spatial effects into the dynamic panel data model may lead to more efficient estimates of the rate of convergence across provinces.

\subsection{Development of Spatial Econometric Models}

Traditional econometrics largely ignored spatial autocorrelation until the development of spatial econometrics. There has been tremendous growth in the spatial econometric literature over the past three decades. Spatial econometrics is an applied field of econometrics that deals with sample data that is collected with reference to location measured as points in space. What distinguishes spatial econometrics from traditional econometrics is that the locational data may be characterized by spatial dependence or spatial heterogeneity (LeSage and Pace, 2009). The idea of spatial dependence, or technically spatial autocorrelation, is similar to the concept of temporal autocorrelation found within the times series literature. As in time series, if this autocorrelation is present and unaccounted for then it could lead to biased or worse inconsistent regression estimates. Anselin (1998) and LeSage and Pace (2009) point out that a local region's characteristics may depend on its neighbors; therefore, ignoring spatial dependence would lead to model misspecification or create biased estimated parameters in an ordinary least squares framework.

The importance of geography is captured in the argument for a "pollution displacement" hypothesis in which higher-income regions are effectively exporting their pollution to lower- 
income regions. One could argue that higher-income regions are inducing greater emissions by importing goods from the more energy intensive, lower-income regions. The pollution haven hypothesis has been explored in context of the environmental Kuznets curve (Stern et al., 1996; Rothman, 1998). If this hypothesis is correct, the carbon dioxide emissions of a poor region adjacent to a rich region would more likely have higher emissions than an equally poor region since distance and the existence of common land borders are important factors in facilitating trade. Geography has been identified as a major determinant of cross-country economic growth due to factors such as the diffusion of technology (Keller, 2004). One could argue that $\mathrm{CO}_{2}$ emission intensity would decrease with technological improvements, so the diffusion of technology could possibly help improve neighboring environmental conditions. Geography is also important because environmental policies promulgated in one region might spill over into other neighboring regions. Local governments, such as a province, most likely assess their policies against those of their neighbors in order to reduce the costs of decision making (Markusen et al., 1995).

Recognizing the importance of geography, Auffhammer and Carson (2008) use a spatial econometrics model to forecast China's emissions using province-level information. Yu (2012) incorporated spatial dependence into a statistical model of China to analyze the influential factors of China's regional energy intensity. The authors found that incorporating spatial dependence into their regression model, in general, improved forecasts and the analysis. Despite their contribution, the authors only estimated the spatial dependence within the dependent variable and the error term in the regression model. They did not explore different data generating processes for the spatial dependence (for example, a spatial Durbin model is specified with a spatially lagged dependent variable and with spatial autocorrelation among the explanatory variables) nor did they offer a rigorous interpretation of the spatial impacts, which include the direct and indirect effects 
estimation of the independent variables. These small deficiencies, therefore present a gap in the literature.

Recent advances in spatial econometrics have led to the development of longitudinal or panel data models that control for spatial autocorrelation. Longitudinal data are simply crosssection observations collected over time. Spatial panel data models are a promising means to examine the spatial and temporal distribution of $\mathrm{CO}_{2}$ emissions. These models offer the dual benefit of potentially controlling for province-level unobserved or heterogeneous fixed effects and spatial dependence.

In general terms, there are two kinds of spatial panel data models. One is a non-dynamic, spatial panel data model, which has received considerable attention in the context of forecasting over the past decade (Kelejian and Robinson, 2000; Baltagi and Li, 2006; Kelejian and Prucha, 2007; Elhorst, 2010; Baltagi et al., 2012). Non-dynamic, spatial panel data models control for both the unobservable province-level fixed effects and potential spatial dependence (autocorrelation) inherent in the underlying data. However, these models do not necessarily control for temporal autocorrelation. Given the recent interests in using spatial panel data models for forecasting purposes, dynamic, spatial panel models make for a nice alternative to the non-dynamic counterparts as they control for both spatial and temporal autocorrelation - hence, these types of models are often called spatio-temporal panel data models. Giacomini and Granger (2004) arguably offered the seminal paper in this literature. In recent years, more and more papers have moved toward forecasting with dynamic, spatial econometric models (Kholodilin et al., 2008; Angulo and Javier Trivez, 2010; Schanne et al., 2010; Kholodilin and Mense, 2012; Ohtsuka and KaKamu, 2013). A few papers have used this methodology to examine the sub-national forecasts 
of carbon dioxide emissions (Auffhammer and Steinhauser, 2007; Auffhammer and Carson, 2008; Auffhammer and Steinhauser, 2012). 


\section{CHAPTER 3: DATA DESCRIPTION ${ }^{4}$}

In this dissertation, the three essays use the same data set, which includes a panel of China's thirty provinces and municipalities for the period 1990-2010 (CSY, 1991-2011). Hong Kong, Macao, Taiwan and Tibet are excluded due to a lack of data. The data are from China Statistical Yearbook (CSY) and China Energy Statistical Yearbook (CESY).

\subsection{Dependent Variable}

In the first and second essays, the dependent variable is $\mathrm{CO}_{2}$ emission intensity, which is calculated as the units of $\mathrm{CO}_{2}$ emissions per unit $\mathrm{GDP}\left(\mathrm{CO}_{2}\right.$ emissions divided by GDP $)$. In the third essay, the dependent variable is $\mathrm{CO}_{2}$ emissions.

Since it is difficult to compare total carbon dioxide emissions across provinces because of the variation in their size and economic activity, I instead analyze province-level emission intensities for the influential factors and the convergence. Emission intensity, which is simply the ratio of overall province emissions to province-level gross domestic product, normalizes emissions across provinces to offer a more compatible apples-to-apples comparison. From a policy sense, an analysis of emission intensity offers a more equitable measure for negotiating multilateral agreements.

Generally, there are four sources data of $\mathrm{CO}_{2}$ emissions in China: the Carbon Dioxide Information Analysis Center (CDIAC), the Energy Information Administration (EIA), International Energy Agency (IEA), and calculation by the IPCC guidelines or the other

\footnotetext{
${ }^{4}$ The data set for this study, in Excel format, is available for replication purposes.
} 
calculation methods. However, there are no statistical data on province level $\mathrm{CO}_{2}$ emissions in China. Therefore, in this research, I estimate the $\mathrm{CO}_{2}$ emissions for each province by following the revised 1996 Intergovernmental Panel on Climate Change's "Guidelines for National Greenhouse Gas Inventories” (IPCC, 1996). The Carbon Dioxide Information Analysis Center, within the U.S. Department of Energy (DOE), defines carbon dioxide emissions as a linear function of fossil fuel combustion and cement manufacturing (Boden, Marland, and Andres, $2013)^{5}$. More specifically, emissions are estimated by multiplying the amount of fuel usage by a thermal conversion factor as determined by the chemical properties of the fuel. Itkonen (2012) offers a simple explanation of how the energy emissions are estimated

$$
C O_{2, t} \equiv \alpha_{\text {oil }} \cdot E_{t}^{\text {oil }}+\alpha_{\text {coal }} \cdot E_{t}^{\text {coal }}+\alpha_{\text {gas }} \cdot E_{t}^{\text {gas }}+\alpha_{\text {flare }} \cdot E_{t}^{\text {flare }}+S_{t}
$$

where $\alpha_{\text {oil }}, \alpha_{\text {coal }}, \alpha_{\text {gas }}, \alpha_{\text {flare }}>0$ are the related thermal conversion factors, or coefficients of carbon emissions. Different organizations, such as the DOE, the institute of Energy Economics of Japan, and the Energy Research Institute of National Development and Reform commission (NDRC) of China, calculate emissions differently by using different coefficients, but the differences are often negligible. The carbon emission coefficients of various types of energy are summarized in Table 3.1. In this research, I choose the coefficients reported by the Energy Research Institute of NDRC of China in 2003. Following the equation offered by Itkonen (2012), I calculate $\mathrm{CO}_{2}$ emissions based on the final energy consumption of three primary types of energy sources in China: coal, petroleum and natural gas (CESY, 1991-2012). I assume that all carbon in the fuel is completely combusted and transformed into carbon dioxide.

\footnotetext{
${ }^{5}$ Due to data limitations, I do not calculate $\mathrm{CO}_{2}$ emissions from cement manufacturing.
} 
Table 3.1 Carbon Emission Coefficients for Various Types of Energy

\begin{tabular}{ccccc}
\hline Data source & Coal & Petroleum & Natural Gas & Hydro-power \\
\hline DOE/EIA & 0.7020 & 0.4780 & 0.3890 & 0 \\
\hline $\begin{array}{c}\text { The Institute of Energy } \\
\text { Economics, Japan }\end{array}$ & 0.7560 & 0.5860 & 0.4490 & 0 \\
\hline $\begin{array}{c}\text { Energy Reseach Institute of } \\
\text { National Development and } \\
\text { Reform Commission, China }\end{array}$ & 0.7476 & 0.5825 & 0.4435 & 0 \\
\hline
\end{tabular}

\subsection{Explanatory Variables}

The first essay seeks to examine the geographical distribution of the driving forces of $\mathrm{CO}_{2}$ emission intensities in China. I estimate a model of $\mathrm{CO}_{2}$ emission intensity based upon per-capita GDP, energy prices, population density, the structure of energy consumption, and the transportation structure. All of the variables are derived from the China Statistic Yearbooks and the provincial Statistical Yearbooks.

The specific definition of each variable is provided here:

1. Per capita GDP (PCGDP): measured by the gross domestic product (GDP) divided by the population. The GDP uses the current real price of each year. I hypothesize that economic growth is one of the most important factors in determining energy consumption and energy efficiency, which then exerts an influence on $\mathrm{CO}_{2}$ emission intensity. The empirical results of Markandya (2006) and Qi (2011) indicated that the decrease of the gap of per-capita GDP between developing and developed countries lead to the decrease of the gap in energy intensity. Yu (2012) also indicated that an increase of province level per-capita GDP reduced the energy intensity in China. Further, Fan et al. (2007) using a decomposition analysis, found that the largest contributor to the decline carbon intensity was a reduction in the percentage of coal in the primary energy mix. This reduction in carbon intensity in tandem with a period of economic expansion is consistent with the 
environmental Kuznets curve literature (Jalil and Mahmud, 2009). Based on this findings, I hypothesize that per-capita GDP will reduce $\mathrm{CO}_{2}$ emission intensity at the province-level in China.

2. Energy prices (EP): as in the standard economic law of demand, I hypothesize that energy prices are an important determinant of energy consumption. I predict that the energy price for a specific fossil fuel will be inversely related to the consumption of that fuel type. Since $\mathrm{CO}_{2}$ is measured based upon energy consumption, I assert that energy prices will be inversely related $\mathrm{CO}_{2}$ emission intensity. In China, the main costs of the energy consumption of each region are the cost of raw materials, fuels, and power. Purchasing price indices for raw materials, fuels and power reflect changes in the level and degree of prices paid by industrial enterprises when they purchase these production inputs, so I will use these indices to represent the energy prices of each province (CSY, 2012a).

3. Population density (PD): is measured as the population divided by the area of each province. Theoretically, as China's population increasingly migrates to urban areas, which have greater access to modern energy technologies (e.g., automobiles, electric power, home heating and cooling). This greater energy consumption is particularly relevant to carbon dioxide emissions since 'consumption-based' rather than 'production-based' measures of carbon dioxide emissions are utilized. The empirical results of Auffhammer and Carson (2008) indicated that population density is positively related to $\mathrm{CO}_{2}$ emissions in China. So I hypothesis a positive relationship between population density and $\mathrm{CO}_{2}$ emission intensity. However, agglomeration effects can optimize the spatial allocation of production and energy resources which could improve production and energy efficiencies.

4. Ratio of coal consumption to total energy consumption (RCC): represented as the percentage of coal consumption of the total energy consumption. Since coal consumption 
accounted for the highest rate of total energy consumption in China (USEIA, 2012), and the power transfer efficiency of coal is relatively lower than petroleum, natural gas and hydro-power, I predict that the higher the ratio of coal consumption the higher the $\mathrm{CO}_{2}$ emission intensity in each province.

5. Total length of highways (TH): is measured as the total kilometers of paved highways at the province level in a particular year. The total length of highways serves as a proxy for activity in the transportation sector. The transportation sector in China accounts for a large portion of $\mathrm{CO}_{2}$ emission intensity. Road transportation alone is consuming about half of the total energy used by the transport sector in China. Advances in technology have led to a reduction in certain pollution emissions, such as nitrogen oxides, sulfur dioxides, and ground-level ozone, but the transportation sector is still the largest and fastest growing consumer of crude oil and the largest producer of $\mathrm{CO}_{2}$ emissions produced from oil (MOT, 2012). Thus, I expect an increase in the total length of highways will increase the $\mathrm{CO}_{2}$ emission intensity.

The description statistic results of all the explanatory variables are presented in Table 3.2.

Table 3.2 Data Description

\begin{tabular}{lllllll}
\hline Variable & Description & Mean & Median & Max & Min & SD \\
\hline CI & $\begin{array}{l}\text { Carbon dioxide emission intensity } \\
\text { (tonne/10K Yuan) }\end{array}$ & 5.581 & 4.216 & 29.163 & 0.538 & 4.197 \\
PCGDP & $\begin{array}{l}\text { Per-capita GDP } \\
\text { (Current Chinese Yuan) }\end{array}$ & 11875.569 & 7160.704 & 78326.132 & 892.609 & 12884.083 \\
EP & $\begin{array}{l}\text { Energy price } \\
\text { (Previous year = 100) }\end{array}$ & 106.460 & 105.600 & 149.900 & 85.300 & 9.300 \\
PD & $\begin{array}{l}\text { Population density } \\
\text { (Person/Square kilometer) }\end{array}$ & 379.167 & 261.001 & 3714.516 & 5.827 & 481.537 \\
RCC & $\begin{array}{l}\text { The ratio of coal consumption to total } \\
\text { energy consumption }\end{array}$ & 0.682 & 0.687 & 0.967 & 0.254 & 0.151 \\
TH & $\begin{array}{l}\text { Total length of Highways } \\
\text { (100 kilometers) }\end{array}$ & 636.639 & 478.030 & 2660.820 & 31.650 & 521.608 \\
\hline Notes: Max, & Min and SD denote the maximum value, minimum value, and standard deviation, respectively.
\end{tabular}


The second essay explores the spatial convergence of $\mathrm{CO}_{2}$ emission intensity and the third essay examines how the spatial panel data models perform in forecasting. Since all the explanatory variables above are hardly considered exogenous, I do not put them into the regression.

Yu and Lee (2012) studied regional growth convergence in the US economy by adopting a spatial, dynamic panel data approach without including any explanatory variables. Angulo and Trívez (2010) analyzed the forecasting ability of a dynamic, spatial panel data model without including explanatory variables as well. Fingleton (2009) evaluated the difference between ex ante predictions (in which case the independent variables are forecasted) and ex post predictions (in which case the independent variables are known). He concluded that ex ante prediction is more problematic and should be analyzed with some caution.

To avoid any potential problems with exogenous and/or ex ante predictions, I follow a similar method as Yu and Lee (2012) and Angulo and Trívez (2010), which does not include any explanatory variables other than the temporal and spatial lag of the dependent variable in the second and third essays. 


\section{CHAPTER 4: SPATIAL ECONOMETRIC TECHNIQUES}

Spatial relationships can be modeled in a variety of ways depending on the relationship between the dependent variable and the explanatory variables. As pointed out by Anselin et al. (2008), when specifying interaction between spatial units, the model may contain a spatially lagged dependent variable or a spatial autoregressive process in the error term, known as the spatial autoregressive model (SAR) / spatial lag model (SLM), or a spatial error model (SEM), respectively. A third model, advocated by LeSage and Pace (2009), is the spatial Durbin model (SDM) that contains a spatially lagged dependent variable and spatially lagged independent variables. By allowing dynamic features in the spatial models, Anselin (2001) and Anselin et al. (2008) introduced spatial dynamic models, including individual time lag, and/or spatial time lag, and/or contemporaneous spatial lag in the models. Yu et al. $(2008,2012)$ and Yu and Lee (2010) further studied the spatial dynamic model with the panel data, which is the spatial dynamic panel data models (SDPD).

\subsection{Spatial Autoregressive Model (SAR) / Spatial Lag Model (SLM)}

The spatial autoregressive model (SAR) is sometimes called the spatial lag model (SLM). The SAR model hypothesis that the value of the dependent variable observed at a particular location is partially determined by a spatially weighted average of neighboring dependent variables. This model cannot be estimated by ordinary least squares (OLS) because of the problem of simultaneity of the dependent variables on the right hand side (RHS) of equation (4-1). The SAR model is formulated as 


$$
Y_{i t}=\rho \sum_{j=1}^{N} W_{i j} Y_{j t}+X_{i t} \beta+\mu_{i}+\eta_{t}+\varepsilon_{i t}, \quad i=1, \ldots, N, t=1, \ldots, T
$$

where $Y_{i t}$ denotes the dependent variable for the cross-sectional unit $i$ at time $t$. The term $\sum_{j} W_{i j} Y_{j t}$ denotes the interaction effect of the dependent variable $Y_{i t}$ with the dependent variables $Y_{j t}$ in neighboring provinces, where $W_{i j}$ is the $i, j^{\text {th }}$ element of a pre-specified nonnegative $(N \times N)$ spatial weights matrix $W$ describing the arrangement of the spatial units in the sample. $X_{i t}$ is a matrix of observations on the explanatory variables.

The parameter $\rho$ denotes the scalar spatial autoregressive parameter. The parameter $\beta$ is a column vector of regression coefficients. The error term, $\varepsilon_{i t}$, is assumed to be independently and identically distributed with a zero mean and variance $\sigma^{2}$. The parameter $\mu_{i}$ denotes individual specific effect for each province, which control for all space-specific time-invariant variables that if omitted could potentially bias the coefficient estimates. The parameter $\eta_{t}$ denotes a time-period specific effect, which control for all time-specific effects whose omission could bias the estimates in a typical time-series study (Baltagi, 2005).

\subsection{Spatial Error Model (SEM)}

The spatial error model (SEM), on the other hand, posits that the dependent variable depends on a set of observed local characteristics and that the error terms are correlated across space. This refers to a situation in which the unobserved shock to province $i$ is affected by unobserved shocks in neighboring regions. The SEM model is specified as

$$
Y_{i t}=X_{i t} \beta+\mu_{i}+\eta_{t}+\phi_{i t}, \quad \phi_{i t}=\delta \sum_{j=1}^{N} W_{i j} \phi_{i t}+\varepsilon_{i t}
$$


where $\phi_{i t}$ reflects the spatially autocorrelated error term and $\delta$ is called the spatial autocorrelation coefficient. According to Anselin et al. (2008), a spatial error specification does not require a theoretical model for a spatial or social interaction process, but, instead, is a special case of a nonspherical error covariance matrix. The term $\sum_{j=1}^{N} W_{i j} \phi_{j t}$ denotes the weighted average value of the neighboring provinces on the error terms.

\subsection{Spatial Durbin Model (SDM)}

A third form of spatial relationship occurs when the dependent variables can be predicted as a function of spatially lagged values of the explanatory variables as well - this is called the spatial Durbin model (SDM). This model extends the SAR model with spatially lagged independent variables. The SDM model is given as

$$
Y_{i t}=\rho \sum_{j=1}^{N} W_{i j} Y_{j t}+X_{i t} \beta+\sum_{j=1}^{N} W_{i j} X_{j t} \theta+\mu_{i}+\eta_{t}+\varepsilon_{i t}
$$

where $\theta$ is a $(K \times 1)$ vector of spatial autocorrelation coefficients on the explanatory variables and $\rho$ denotes a scalar spatial autocorrelation coefficient on the dependent variables in this particular specification. The term $\sum_{j=1}^{N} W_{i j} X_{j t}$ denotes the weighted average value of the neighboring provinces on the independent variables.

This model can then be used to test the hypothesis $H_{0}: \theta=0$ and $H_{0}: \theta+\delta \beta=0$. The first hypothesis examines whether the SDM model can be simplified to the SAR model, and the second hypothesis whether it can be simplified to the SEM model (Burridge, 1981; Elhorst, 2012). Both tests follow a chi-squared distribution. 


\subsection{Spatial Dynamic Panel Data Model (SDPD)}

The spatial panel data models include both spatial and dynamic effects to investigate the state dependence and serial correlations. Anselin (2001) and Anselin (2008) divide spatial dynamic models into four categories, namely, "pure space recursive" if only a spatial time lag is included; "time-space recursive" if only a spatial time lag is included; "time-space simultaneous" if an individual time lag and a contemporaneous spatial lag are specified; and "time-space dynamic" if all forms of lags are included. The "time-space dynamic" model corresponds to the SDPD model if individual effects are included. For the SDPD model, Yu et al. $(2008,2012)$ and Yu and Lee (2010) studied the stable, spatial cointegration, and unit root models, respectively. In this study, I will estimate the model with general SDPD specification. A general SDPD model can be specified as

$$
Y_{i t}=\rho \sum_{j=1}^{N} W_{i j} Y_{j t}+\gamma Y_{i, t-1}+\lambda \sum_{j=1}^{N} W_{i j} Y_{j, t-1}+X_{i t} \beta+\mu_{i}+\eta_{t}+\varepsilon_{i t}
$$

where $\gamma$ captures the pure dynamic effect, and it is a scalar parameter on the temporally lagged dependent variable. $\lambda$ captures the spatial-time effect, and it is the spatial autocorrelation coefficient on the temporally lagged dependent variable. The term $\sum_{j=1}^{N} W_{i j} y_{j, t-1}$ denotes the weighted average value of the neighboring provinces on the temporal dependent variable.

\subsection{Spatial Weights Matrix}

In the above spatial models, the term $W$ in each equation denotes the spatial weights matrix, which is a compact reflection of the geographic relationship among different provinces. In the literature, there are a large number of weighting matrix specifications, for instance, binary 
contiguity matrix, distance function matrix, inverse distance matrix, $k$-nearest neighbors matrix, and so on. The binary contiguity matrix and the distance matrix are the most common specifications to be used.

The neighboring relation in the binary contiguity matrix is determined by observing whether the regions share a common border. That is, if two regions $i$ and $j$ are neighbors, then the matrix elements $w_{i j}=1$, otherwise $w_{i j}=0$. The element in the distance function matrix is determined by the distant function $w_{i j}=f\left(d_{i j}\right)$, where $d_{i j}$ refers to the distance between the geometric centroid (or capitals) of region $i$ and region $j$. For additional information about the spatial weights matrix the reader is referred to LeSage and Pace (LeSage and Pace, 2009).

In this study, the spatial weights matrix is specified as the binary contiguity matrix. Generally, the spatial weighed matrix is normalized according to row standardization, in other words, the sum of the elements $W_{i j}$ in each row equals one after normalization. This transformation of the spatial weights matrix provides for an intuitive explanation in that any variable premultiplied by the spatial weight matrix will represent a weighted average of the surrounding observations. 


\section{CHAPTER 5: SPATIAL ANALYSIS OF CHINA PROVINCE LEVEL CO $\mathrm{CO}_{2}$ EMISSION INTENSITY ${ }^{6}$}

This essay analyzes the spatial dependence by specifying novel spatial panel data models which control for spatial effects across both space and time. That is, I estimate a model of $\mathrm{CO}_{2}$ emission intensity based upon per-capita GDP, energy prices, population density, the structure of energy consumption, and the transportation structure at the province level from 1990-2010. I find statistically significant, spatial autocorrelation (dependence) among these driving forces and $\mathrm{CO}_{2}$ emission intensities at the province-level in China. This spatial autocorrelation implies that any policies implemented in one province will have spillover effects in neighboring province. The determination of such spillovers is important for understanding the direct and indirect effects of province-level policies adopted in China.

This essay offers four unique contributions to the literature: (1) by more explicitly considering and testing for the types of spatial dependence within the relationship between energyrelated emissions and economic forces; (2) using recently developed, spatial panel data models and diagnostics to determine the most appropriate spatial econometric model; (3) offering a more rigorous interpretation of both the direct and indirect spatial impacts (spillovers); and, (4) extending the data to consider the years 1990-2010, which is important for capturing recent developments in province-level energy consumption and economic growth.

\footnotetext{
${ }^{6}$ This essay is based upon the paper: Zhao, X., Burnett, J.W., Fletcher, J.J., 2014. Spatial Analysis of China Province-Level $\mathrm{CO}_{2}$ Emission Intensity. Renewable and Sustainable Energy Reviews 33, 1-10.
} 


\subsection{Empirical Approach}

\subsubsection{Regression Model}

I specify the regression model as follows:

$$
c i_{i t}=\beta_{0}+\beta_{1} p c g d p_{i t}+\beta_{2} e p_{i t}+\beta_{3} p d_{i t}+\beta_{4} r c c_{i t}+\beta_{5} t h_{i t}+\mu_{i}+\eta_{t}+\varepsilon_{i t}
$$

where all variables are defined as natural logarithms in order to interpret the coefficients as elasticities. The parameter $\mu_{i}$ denotes the individual effect (or heterogeneity) for each province and $\eta_{t}$ denotes a common time effect. I treat the individual effect as fixed meaning that I assume that this variable is correlated with the explanatory variables and approximately fixed over time for each province within the sample. If I estimate (5-1) without controlling for the individual effect, then estimation may result in omitted variable bias if the fixed effect is correlated with the explanatory variable. The individual effect can be interpreted as characteristics within provinces that do not change over time such as unobservable geographic characteristics. The time period effects control for time-specific shocks that affects all provinces in a given period of time; e.g., national policies that affect $\mathrm{CO}_{2}$ emissions across all provinces in China.

In this study, I will estimate the SAR, SEM and SDM models based on this general regression model. The specification of the spatial models have introduced in Chapter 4.

\subsubsection{Estimation Method}

\subsubsection{Global Spatial Autocorrelation}

The global spatial autocorrelation (i.e., a general measure of spatial dependence) of China's overall (energy-related) $\mathrm{CO}_{2}$ emission intensity can be measured by Moran's I index. The formula for calculating global Moran's I index is 


$$
\begin{aligned}
\text { Moran's } I & =\frac{\sum_{i} \sum_{j} \omega_{i j}\left(Y_{i}-\bar{Y}\right)\left(Y_{j}-\bar{Y}\right)}{S^{2} \sum_{i} \sum_{j} \omega_{i j}} \\
S^{2} & =\frac{1}{n} \sum_{i}\left(Y_{i}-\bar{Y}\right) \\
\bar{Y} & =\frac{1}{n} \sum_{i} Y_{i}
\end{aligned}
$$

where $Y_{i}$ and $Y_{j}$ represent $\mathrm{CO}_{2}$ emission intensity of province $i$ and $j$, respectively. The term $w_{i j}$ denotes the element in the $i^{\text {th }}$ row and $j^{\text {th }}$ column of the spatial weight matrix. The global Moran's I index is defined over the interval $[-1,1]$. Positive Moran's I values imply positive spatial autocorrelation (or spatial dependence), where a value of one indicates perfect correlation. Conversely, negative values imply negative autocorrelation, where a value of negative one indicates perfect dispersion. A zero value indicates a random spatial pattern. The significance of Global Moran's I index can be tested by standard z-statistics.

\subsubsection{Spatial Econometric Analysis ${ }^{7}$}

In this study, I follow the specification tests outlined in Elhorst (2012). The first step is to test the standard, non-spatial panel models against the SAR and SEM models. To test whether the spatial effects model (against the non-spatial models) offer an appropriate specification I employ a series of Lagrange Multiplier (LM) tests.

The second step is to investigate the joint significance of individual fixed effects and timeperiod fixed effects. The hypothesis tests are

$$
H_{0}: \mu_{1}=\mu_{2}=\ldots=\mu_{N}=0
$$

\footnotetext{
${ }^{7}$ The regressions Ire conducted using Matlab code provided by James LeSages and Paul Elhorst. Matlab is a commercially developed numerical computing environment and programming language. For additional information about Matlab, the reader is referred to the developer's website: http://www.mathworks.com/products/matlab.
} 


$$
H_{0}: \eta_{1}=\eta_{2}=\ldots=\eta_{T}=0
$$

$H_{0}: \mu_{1}=\mu_{2}=\ldots=\mu_{N}=0$ states that the individual fixed effects are jointly insignificant, and $H_{0}: \eta_{l}=$ $\eta_{2}=\ldots=\eta_{T}=0$ states that the time-period fixed effects are jointly insignificant. Likelihood ratio (LR) tests are used to check these null hypotheses. If the p-value is less than five percent, then I reject the null hypothesis of joint insignificance (Elhorst, 2012).

If I fail to reject the spatial model in the previous step, then the third step will be to test whether the SDM model can be simplified to the SAR or SEM model. The hypothesis tests for the third step are

$$
\begin{aligned}
& H_{0}: \delta=0 \\
& H_{0}: \delta+\rho \beta=0 .
\end{aligned}
$$

$H_{0}: \delta=0$ examines whether the spatial Durbin model can be simplified to the spatial lag model, and $H_{0}: \delta+\rho \beta=0$ examines whether it can be simplified to the spatial error model. Both tests follow a chi-squared distribution. A rejection of both hypotheses suggests that the spatial Durbin model provides the best fit to the data. Conversely, a failure to reject the first hypothesis suggests that the spatial lag model best describes the data. A failure to reject (5-5) can be balanced against the results of the (robust) LM tests for the spatial autoregressive model. Similarly, a failure to reject the second hypothesis (5-6) suggests that the spatial error model best describes the data which can also be balanced against the results of the (robust) LM tests for the spatial error model.

The last step is to estimate the spatial spillover effects of $\mathrm{CO}_{2}$ emission intensity. I follow LeSage and Pace (2009) by estimating the direct and indirect effects of the explanatory variables. Direct effects estimates measure the impact of changing an independent variable on the dependent variable of a spatial unit. Loosely speaking, the indirect effects estimates measure the impact of changing an independent variable in a particular unit on the dependent variable of all other units. 


\subsection{Estimation Results}

\subsubsection{Global Spatial Autocorrelation}

Table 5.1 displays China's Global Moran's I index of carbon dioxide emission intensity and its significance in various periods from 1990 to 2010. The overall Moran's I over twenty year period is 0.394 , which indicates positive spatial correlation at the one percent significant level. In each period, the test reveals that $\mathrm{CO}_{2}$ emission intensity displays positive spatial autocorrelation at a five percent significant level. Recall, the $\mathrm{CO}_{2}$ emissions are estimated based upon energy consumption, so positive spatial autocorrelation in this sense is referring to the spatial dependence of energy consumption. This indicates that China's $\mathrm{CO}_{2}$ emission intensity tend to cluster together. Specially, I find that provinces with high $\mathrm{CO}_{2}$ emission intensities have a tendency to cluster together, whereas the provinces with low $\mathrm{CO}_{2}$ emission intensities cluster together.

Despite the findings of the spatial autocorrelation of $\mathrm{CO}_{2}$ emission intensity, the Moran's I test only assesses the overall pattern and trend. Moran's I is only effective when the spatial pattern is consistent across the provinces. If some of the provinces have positive spatial autocorrelation while others have negative spatial autocorrelation, then the effects could offset one other. In which case, the global Moran's I test may reveal non-spatial autocorrelation characteristics.

Table 5.1 Moran's I Index of China's $\mathrm{CO}_{2}$ Emission Intensity

\begin{tabular}{lccccc}
\hline & $1990-2010$ & $1990-1995$ & $1996-2000$ & $2001-2005$ & $2006-2010$ \\
\hline Moran's I & 0.394 & 0.450 & 0.389 & 0.274 & 0.205 \\
Z-Statistic & 3.650 & 4.129 & 3.607 & 2.630 & 2.034 \\
P-value & 0.000 & 0.000 & 0.000 & 0.008 & 0.042 \\
Significant level & $* * *$ & $* * *$ & $* * *$ & $* * *$ & $* *$ \\
\hline \multicolumn{4}{l}{ Notes: The symbols $* * *, * *, *$ denote a significance level of one, five and ten percent, respectively. } \\
\hline
\end{tabular}

To further examine the clustering of among provinces, I employ a Moran's I scatterplot displayed in Figure 5.1. In this scatterplot, the horizontal axis refers to the deviation of provincial 
average carbon dioxide emission intensity from 1990 to 2010, whereas the vertical axis refers to the spatial lags of the deviation of the average carbon dioxide emission intensity. I calculate the spatial lags by using a first-order contiguity spatial weight matrix, which produces an average measure of carbon dioxide emission intensity among neighboring provinces. The four quadrants in the scatter plot depict:

1. $\mathrm{HH}$ clustering (quadrant $\mathrm{I}$ ) - provinces with high $\mathrm{CO}_{2}$ emission intensity are associated with neighboring province with high $\mathrm{CO}_{2}$ emission intensity (the star points);

2. LH clustering (quadrant II) - provinces with low $\mathrm{CO}_{2}$ emission intensity are associated with neighboring provinces with high $\mathrm{CO}_{2}$ emission intensity (the circle points)

3. LL clustering (quadrant III) - provinces with low $\mathrm{CO}_{2}$ emission intensity are associated with neighboring provinces with low $\mathrm{CO}_{2}$ emission intensity (the cross points)

4. HL clustering (quadrant IV) - provinces with high $\mathrm{CO}_{2}$ emission intensity are associated with neighboring provinces with low $\mathrm{CO}_{2}$ emission intensity (the square points). 


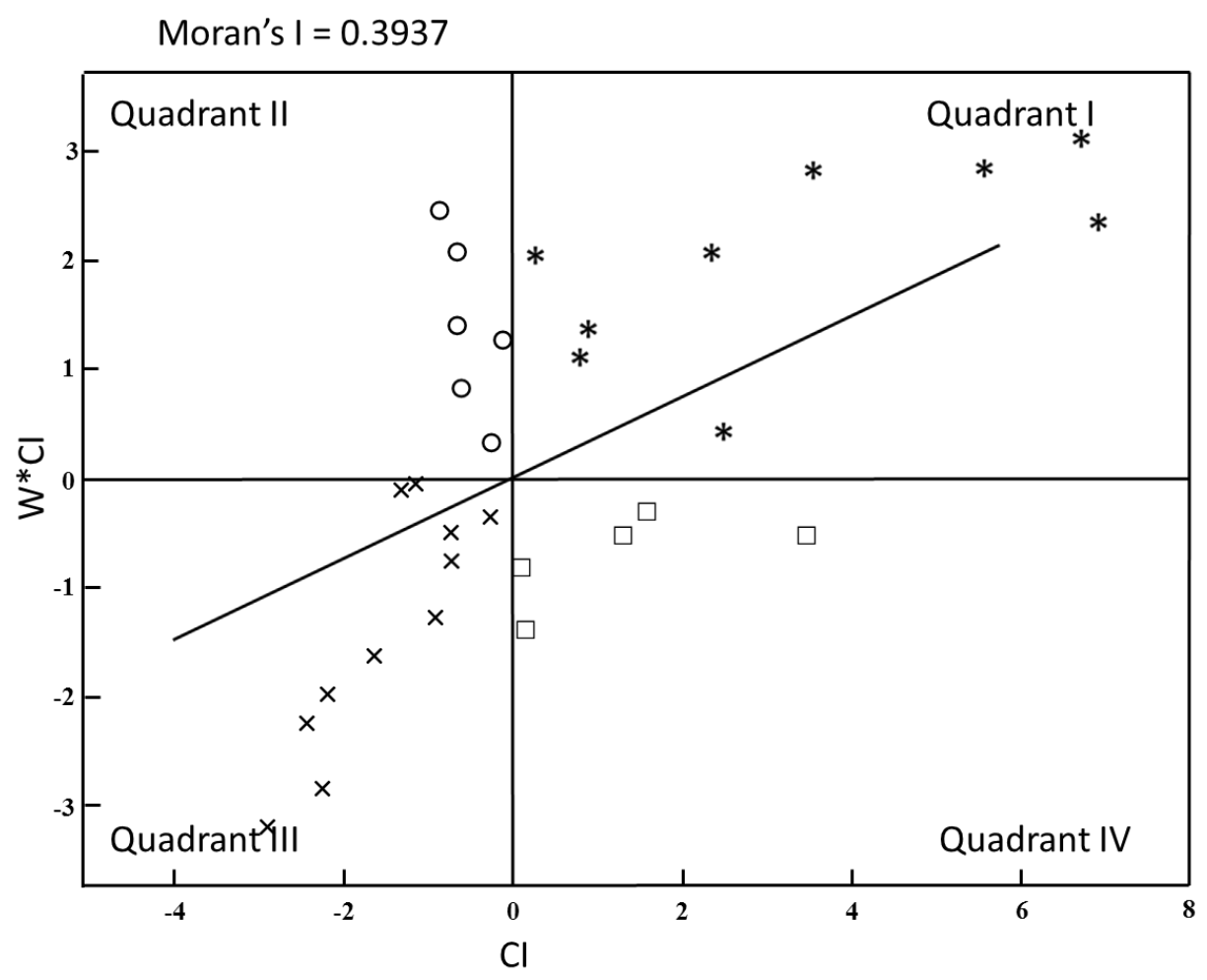

Figure 5.1 Moran Scatterplot of China's Provincial $\mathrm{CO}_{2}$ Emission Intensity (1990-2010)

The results in Figure 5.1 consist of the following:

1. Nine provinces in quadrant I: Heilongjiang, Liaoning, Inner Mongolia, Hebei, Shanxi, Shaanxi, Ningxia, Gansu, and Xinjiang

2. Six provinces in quadrant II: Beijing, Tianjin, Henan, Shandong, Sichuan, and Chongqing

3. Ten provinces in quadrant III: Shanghai, Jiangsu, Zhejiang, Hubei, Hunan, Jiangxi, Fujian, Guangdong, Hainan, and Yunnan

4. Five provinces in quadrant IV: Qinghai, Anhui, Guizhou, Guangxi and Jilin

In this analysis, $63.33 \%$ (nineteen provinces) show similar characteristics of spatial autocorrelation. Further, 30\% (nine provinces) in quadrant I and 33.33\% (ten provinces) in quadrant III demonstrate similar characteristics of positive spatial autocorrelation. On the other 
side, $20 \%$ (six provinces) in quadrant II and $16.67 \%$ (five provinces) in quadrant IV demonstrate negative spatial autocorrelation. This means that the spatial autocorrelation and dispersion of provincial $\mathrm{CO}_{2}$ emission intensity exist at the same time.

The Moran's I analysis implies that China has significant clustering of emissions in high emitting provinces and significant clustering of emissions in low emitting provinces for the period of observation. The statistically significant, spatial autocorrelation among provinces implies that standard ordinary least squares regressions of the drivers of emissions may lead to estimation bias in the regression results. Therefore, I test whether a spatial panel data model is preferable to nonspatial models in the analysis of the drivers of emissions at the province-level in China.

\subsubsection{Empirical Results of Spatial Econometric Models}

The estimation results for the non-spatial panel data models are reported in Table 5.2. Columns (1) through (4) represent the estimation results of pooled OLS, individual fixed effects only, time-period fixed effects only, and individual and time-period fixed effects, respectively. When using the classical LM tests, both the hypothesis of no spatially lagged dependent variable and the hypothesis of no spatially autocorrelated error term are strongly rejected at a one percent significance level with the exception of including both the individual and time-period fixed effects. When using the robust LM tests, the hypothesis of no spatially lagged dependent variable is still rejected at a one percent significance level for each of the specifications. The hypothesis of no spatial autocorrelated error term is rejected at one percent significance level when individual fixed effects are included and at five percent significance level when the time-period fixed effects are included. But this same hypothesis (robust LM spatial error) cannot be rejected for the pooled OLS. These results seem to imply that the SAR model is a more appropriate specification than the non- 
spatial model as I find fairly consistent evidence across all models to reject the null hypothesis of no spatial lag. I find mixed results to reject the hypothesis for spatially autocorrelated error term.

Table 5.2 Estimation results of non-spatial panel data models

\begin{tabular}{|c|c|c|c|c|}
\hline Determinants & Pooled OLS & $\begin{array}{l}\text { Individual Fixed } \\
\text { effects }\end{array}$ & $\begin{array}{l}\text { Time-period fixed } \\
\text { effects }\end{array}$ & $\begin{array}{l}\text { Individual and time- } \\
\text { period fixed effects }\end{array}$ \\
\hline \multirow[t]{2}{*}{ pcgdp } & $-0.413 * * *$ & $-0.642 * * *$ & $-0.366^{* * *}$ & $-0.755^{* * *}$ \\
\hline & $(-23.038)$ & $(-21.822)$ & $(-10.382)$ & $(-7.466)$ \\
\hline \multirow{2}{*}{ ep } & $0.476 * *$ & $0.427 * * *$ & -0.255 & 0.199 \\
\hline & $(2.574)$ & $(3.737)$ & $(-0.743)$ & $(0.896)$ \\
\hline \multirow[t]{2}{*}{$\mathrm{pd}$} & $-0.180 * * *$ & $-1.007 * * *$ & $-0.193 * * *$ & $-1.153 * * *$ \\
\hline & $(-13.119)$ & $(-5.328)$ & $(-14.163)$ & $(-5.610)$ \\
\hline \multirow[t]{2}{*}{$\mathrm{rcc}$} & $1.036 * * *$ & 0.149 & $1.061 * * *$ & 0.080 \\
\hline & $(16.188)$ & $(1.441)$ & $(17.068)$ & $(0.806)$ \\
\hline \multirow[t]{2}{*}{ th } & $-0.226 * * *$ & $0.207 * * *$ & $-0.228 * * *$ & 0.056 \\
\hline & $(-12.414)$ & $(5.032)$ & $(-10.362)$ & $(1.035)$ \\
\hline Intercept & $\begin{array}{l}5.683 * * * \\
(6.229)\end{array}$ & NA & NA & NA \\
\hline$\sigma^{2}$ & 0.137 & 0.049 & 0.123 & 0.044 \\
\hline $\mathrm{R}^{2}$ & 0.723 & 0.900 & 0.751 & 0.912 \\
\hline Log Like & -251.420 & 55.585 & -219.016 & 91.450 \\
\hline Sample & 600 & 600 & 600 & 600 \\
\hline LM Spatial lag & $94.862 * * *$ & $60.1405 * * *$ & $26.821 * * *$ & 0.876 \\
\hline Robust LM Spatial lag & $57.297 * * *$ & $71.2093 * * *$ & $32.183 * * *$ & $7.692 * * *$ \\
\hline LM Spatial error & $37.572 * * *$ & $15.2978 * * *$ & $5.624 * *$ & 0.062 \\
\hline Robust LM Spatial error & 0.007 & $26.3666 * * *$ & $10.986 * * *$ & $6.878 * * *$ \\
\hline
\end{tabular}

To investigate the joint significance of the individual fixed effects and time-period fixed effects, I perform the LR tests. The results are shown in Table 5.3. The null hypothesis that the individual fixed effects are jointly insignificant is rejected at a one percent level, and the null hypothesis that the time-period fixed effects are jointly insignificant is also rejected at a one percent level. These test results seem to justify the extension of the model with the two-way fixed effects model- i.e., include both the individual fixed effects and time-period fixed effects. I also conduct a Hausman test to further test the correct panel data specification between a fixed effects 
and random effects model. The Hausman test results imply that the fixed effects model is the more appropriate specification.

Table 5.3 Post diagnostic tests of joint significance of fixed effects

\begin{tabular}{|c|c|c|c|}
\hline Test & Chi-Squared Statistic & Degree of Freedom & $\mathrm{P}$-value \\
\hline \multicolumn{4}{|l|}{ LR } \\
\hline Individual fixed effects & 620.9317 & 30 & 0.0000 \\
\hline Time-period fixed effects & 71.7303 & 20 & 0.0000 \\
\hline Hausman & 44.6832 & 11 & 0.0000 \\
\hline
\end{tabular}

Note: All tests follow a chi-squared distribution with K degrees of freedom.

Table 5.4 Estimation results of spatial panel data models and interaction effects

\begin{tabular}{|c|c|c|c|}
\hline Determinants & SAR & SEM & SDM \\
\hline pcgdp & $\begin{array}{l}-0.640 \text { *** } \\
(-6.300)\end{array}$ & $\begin{array}{l}-0.749 * * * \\
(-7.118)\end{array}$ & $\begin{array}{l}-0.519 * * * \\
(-5.073)\end{array}$ \\
\hline ep & $\begin{array}{l}0.142 \\
(0.639)\end{array}$ & $\begin{array}{l}0.204 \\
(0.888)\end{array}$ & $\begin{array}{l}0.106 \\
(0.491)\end{array}$ \\
\hline $\mathrm{pd}$ & $\begin{array}{l}-1.146 * * * \\
(-5.550)\end{array}$ & $\begin{array}{l}-1.165 * * * \\
(-5.440)\end{array}$ & $\begin{array}{l}-1.282 * * * \\
(-5.941)\end{array}$ \\
\hline $\mathrm{rcc}$ & $\begin{array}{l}0.124 \\
(1.243)\end{array}$ & $\begin{array}{l}0.083 \\
(0.809)\end{array}$ & $\begin{array}{l}0.257 * * * \\
(2.624)\end{array}$ \\
\hline th & $\begin{array}{l}0.073 \\
(1.341)\end{array}$ & $\begin{array}{l}0.054 \\
(0.962)\end{array}$ & $\begin{array}{l}0.150 * * * \\
(2.748)\end{array}$ \\
\hline$\rho$ & $\begin{array}{l}0.342 * * * \\
(7.175)\end{array}$ & NA & $\begin{array}{l}0.106 * * \\
(1.950)\end{array}$ \\
\hline$\lambda$ & NA & $\begin{array}{l}0.094 * \\
(1.658)\end{array}$ & NA \\
\hline $\mathrm{W}^{*}$ pcgdp & NA & NA & $\begin{array}{l}-0.702 * * * \\
(-8.247)\end{array}$ \\
\hline $\mathrm{W}^{*}$ ep & NA & NA & $\begin{array}{l}0.203 \\
(0.552)\end{array}$ \\
\hline $\mathrm{W}^{*} \mathrm{pd}$ & NA & NA & $\begin{array}{l}1.062 * * * \\
(2.656)\end{array}$ \\
\hline W*rcc & NA & NA & $\begin{array}{l}-0.343^{*} \\
(-1.802)\end{array}$ \\
\hline $\mathrm{W}^{*}$ th & NA & NA & $\begin{array}{l}0.275^{* *} \\
(2.362) \\
\end{array}$ \\
\hline$\sigma^{2}$ & 0.044 & 0.047 & 0.039 \\
\hline$R^{2}$ & 0.918 & 0.912 & 0.927 \\
\hline Sample & 600 & 600 & 600 \\
\hline Log Like & 84.973 & 91.496 & 147.949 \\
\hline $\begin{array}{l}\text { Note: All varia } \\
\text { one, five and te } \\
\text { represent t-stat }\end{array}$ & $\begin{array}{l}\text { re measure } \\
\text { cent signific } \\
\text { s. }\end{array}$ & $\begin{array}{l}\text { logs. The sy } \\
\text { respectively }\end{array}$ & $\begin{array}{l}\text { rs in the parentheses } \\
\text { re }\end{array}$ \\
\hline
\end{tabular}


Table 5.4 gives the estimation results of $\mathrm{CO}_{2}$ emission intensity according to the three spatial specification panel data models (as per the LR test results I include both the individual and time-period fixed effects).

Since the Lagrange Multiplier test results suggest that the spatial models are a more appropriate specification than the non-spatial models, I will continue to test which spatial model offers the best fit for the data. I perform both the Wald test and LR test to test the hypothesis whether the SDM model could be simplified to the SAR model or SEM model. The results are reported in Table 5.5. According to the Wald test result and LR test result, the null hypothesis (55) that the SDM model can be simplified to the SAR model is rejected at a one percent significance level. Similarly, the null hypothesis (5-6) that the SDM model can be simplified to a SEM model is also rejected at a one percent significance level based on the Wald test result and LR test result. These results imply that both the spatial lag model and spatial error model are rejected in favor of the spatial Durbin model. Therefore, I conduct a sensitivity analysis of the SDM model.

Table 5.5 Post diagnostic tests of spatial specification

\begin{tabular}{|c|c|c|c|c|}
\hline Test & & Chi-Squared Statistic & Degree of Freedom & P-value \\
\hline \multicolumn{5}{|l|}{ LR } \\
\hline & Spatial lag & 125.952 & 5 & 0.0000 \\
\hline & Spatial error & 112.906 & 5 & 0.0000 \\
\hline \multicolumn{5}{|c|}{ Wald test } \\
\hline & Spatial lag & 105.233 & 5 & 0.0000 \\
\hline & Spatial error & 117.64 & 5 & 0.0000 \\
\hline
\end{tabular}

Note: All tests follow a chi-squared distribution with K degrees of freedom.

As can be gleaned from the estimated results in Table 5.4, the coefficients of independent variables are basically consistent with the theoretical expectations offered in Chapter 3. Just focusing on the SDM coefficient estimates, an interpretation of the coefficient on per-capita GDP is that a ten percent increase of per-capita GDP is associated with $5.19 \%$ decrease of the $\mathrm{CO}_{2}$ 
emission intensity (holding all else constant). An interpretation of the ratio of coal consumption to total energy consumption is that a ten percent decrease will lead to a $2.57 \%$ decrease in emission intensity. Similarly, the total length of highways coefficient implies that a ten percent increase will lead to $1.5 \%$ increase of $\mathrm{CO}_{2}$ emission intensity.

These results imply that an improvement in the economic performance at the province level will lead to a decrease of $\mathrm{CO}_{2}$ emission intensity (as reflected in the coefficient on per-capita GDP); while increasing the ratio of coal consumption to total energy consumption and the total length of highways will lead to the increase of the $\mathrm{CO}_{2}$ emission intensity. The coefficient on the ratio of coal to total energy consumption implies that replacing coal consumption with non-coal energy consumption is an effective mechanism to decrease $\mathrm{CO}_{2}$ emission intensity. Further, the coefficient on the total length of highways suggests that technological advancements in energy efficiency (i.e., barring any rebound effects) of the transportation sector may play a role in decreasing $\mathrm{CO}_{2}$ emission intensity.

The results for the SDM in Table 5.4 also suggest that a ten percent increase in population density is associated with a $12.82 \%$ decrease of the $\mathrm{CO}_{2}$ emission intensity, which implies that agglomeration effects are leading to an improvement in energy efficiency which in turn reduces emission intensity. Contrary to expectations, I do not find a significant relationship between energy prices and $\mathrm{CO}_{2}$ emission intensity, which implies that energy prices do not play a role in reducing $\mathrm{CO}_{2}$ emission intensity. A possible explanation for this lack of statistical significance is that the Chinese government subsidizes energy prices thereby keeping prices artificially below the market price.

Given the statistically significant spatial autocorrelation coefficient, $\rho$, the parameter estimates in the two-way fixed effects spatial Durbin model cannot be interpreted as marginal 
effects as in the case of non-spatial models. Therefore, following LeSage and Pace (2009), I estimate the direct and indirect effects to yield an interpretation of the spatial spillover effects. The direct and indirect effects of each explanatory variable are reported in Table 5.6. The difference between the direct effects (Table 5.6) and the coefficient estimates (Table 5.4) are due to the feedback effects that arise as a result of impacts passing through neighboring provinces and back to the provinces themselves. The feedback effects include both the impacts from the spatially lagged dependent variable $\left(\rho \sum W_{i j} Y_{j t}\right)$ and the impacts from the spatially lagged value of the explanatory variable itself $\left(\sum W_{i j} X_{j t} \theta\right)$.

Table 5.6 Direct \& Indirect effects of SDM model

\begin{tabular}{llll}
\hline Determinants & Direct Effect & Indirect Effect & Total Effect \\
\hline pcgdp & $-0.533 * * *$ & $-0.827 * * *$ & $-1.360 * * *$ \\
& $(-5.412)$ & $(-7.594)$ & $(-9.626)$ \\
ep & 0.105 & 0.231 & 0.336 \\
& $(0.466)$ & $(0.536)$ & $(0.697)$ \\
pd & $-1.252^{* * *}$ & $1.002 * *$ & -0.250 \\
& $(-5.738)$ & $(2.278)$ & $(-0.581)$ \\
rcc & $0.247 * *$ & -0.353 & -0.106 \\
& $(2.410)$ & $(-1.728)$ & $(-0.461)$ \\
th & $0.157 * * *$ & $0.310^{* *}$ & $0.467 * * *$ \\
& $(2.934)$ & $(2.457)$ & $(3.463)$ \\
\hline
\end{tabular}

Note: All variables are measured as natural logs. The symbols ***, ** and * denote a one, five and ten percent significance level, respectively. Numbers in the parentheses represent t-stat values.

The results in Table 5.6 reveal that the direct effects of all the explanatory variables (with the exception of energy prices) are statistically significant. Among the direct effects, per-capita GDP, population density, and the length of highways are significant at one percent level. The direct effect of the ratio of coal to total energy consumption is significant at the five percent level. 
In the non-spatial model, the indirect effects are set, by construction, to zero; however, based on the $t$-statistics calculated from a set of 1,000 simulated parameter values (LeSage and Pace, 2009) in the two-way fixed effects spatial Durbin model, there are three statistically significant indirect effects. The indirect effect of per-capita GDP is significant at the one percent level, and the indirect coefficients on population density and length of highways are significant at a five percent level. These coefficients imply that a change per-capita GDP, population density, and length of highways in one particular province has an average cumulative effect on the corresponding variables in neighboring provinces.

The statistically significant coefficients on both the direct effect and indirect effect of percapita GDP are negative which implies that the own-province per-capita GDP increases will reduce the $\mathrm{CO}_{2}$ emission intensity of both own province and neighboring provinces. The coefficients of both the direct effect and indirect effect of total length of highways are positive and significant, and the implication is that an increase in own-province highway construction leads to an increase of both own province and neighboring province $\mathrm{CO}_{2}$ emission intensity. The negative coefficient on the direct effect and positive coefficient on the indirect effect of population density imply that own-province population density increases will decrease own $\mathrm{CO}_{2}$ emission intensity but increase the emission intensity of neighboring provinces.

\subsection{Conclusions}

In this essay, I analyzed the influence of economic activity, energy prices, population density, energy consumption structure, and transportation structure on $\mathrm{CO}_{2}$ emission intensity in China. I used spatial econometrics methods so as to avoid the potential coefficient bias from ignoring spatial autocorrelation as in OLS estimation. 
The regression results suggest that per-capita GDP reduces $\mathrm{CO}_{2}$ emission intensity, which implies that promoting the local economic development, may help to reduce $\mathrm{CO}_{2}$ emission intensity. These results suggest that economic development can still be compatible with $\mathrm{CO}_{2}$ emission mitigation as China is in the middle stages of industrialization. A possible policy prescription for China would be to target a rate of increase per-capita GDP but weigh such targets with policies to reduce emission intensities.

The findings suggest that an increase in population density leads to a decrease of $\mathrm{CO}_{2}$ emission intensity. The provinces with large population density, such as Shanghai, Beijing and Tianjin, have relative low $\mathrm{CO}_{2}$ emission intensity; and the provinces with small population density, such as Xinjiang, Ningxia and Inner Mongolia, have relatively high $\mathrm{CO}_{2}$ emission intensity. This finding suggests that population concentration could improve the production efficiency and energy efficiency so as to decrease emission intensities. This does not imply, however, that population control should be unmitigated. This study also finds that an increase in the ratio of coal consumption to total energy consumption leads to a significant increase in $\mathrm{CO}_{2}$ emission intensity. Compared with the other energy resources, the power transfer efficiency of coal is relatively low. This finding may suggest that the Chinese government should encourage the development of less carbon-intensive energy resources such as natural gas or renewables.

The regression results also suggest that an increase in the total length of highways leads to an increase of $\mathrm{CO}_{2}$ emission intensity. This finding suggests that the Chinese government should continue to encourage technological advancements which reduce emission intensity and encourage further fuel efficiency standards in its transportation sector, especially as China's transportation infrastructures continues to grow at an accelerated pace. 
Moreover, I find that the energy prices in China have no significant effect on the $\mathrm{CO}_{2}$ emission intensity, which differed from my expectations. A possible explanation for this is that government policies such as subsidies and price controls have artificially lowered energy prices in order to stimulate economic growth. China has recently instituted market-oriented reforms so that the price of fossil fuels more accurately reflects the true market cost (Hang and Tu, 2007). This finding may suggest that the Chinese government should further deregulate energy prices to reduce artificial price distortions.

I also find that per-capita GDP, population density, and total length of highways have statistically significant effects on both the own province and the neighboring province elasticities. Both of these findings are consistent with the hypothesis of economic distance (Conley and Ligon, 2002). These findings suggest that the Chinese government should promote the sharing and exchange of information and technology across provinces, and develop appropriate policies to strengthen cross-province development.

The findings have implications for inter- and intra-regional land use planning and economic policy. Land use regulations can delay residential development and increase development costs, but such regulations can address market failures (e.g., addressing the social costs of global climate change) and ensure a well-organized urban spatial structure (Kim and Hewings, 2013). The regression results from the spatial model imply that the driving forces of $\mathrm{CO}_{2}$ emissions are inter-related at the province-level in China. This inter-relatedness suggests that China's province-level governments (and municipal governments) should offer coordinated land use planning and economic policy. Raising barriers to development can assist in labor relocation and possibly social mobility as increasing numbers move from rural areas to the heavily urbanized parts of the country. As the population in general becomes more affluent and educated, the 
populace can begin to apply pressure on the government to reduce $\mathrm{CO}_{2}$ emissions and other harmful pollutants that have plagued the country over the past couple of decades.

This study suffers from some limitations including the problem of measurement error. The measure of $\mathrm{CO}_{2}$ emissions, which is consistent with the rest of literature, is based upon the consumption of energy, so it is subject to mis-measurement. An additional problem is that I specified a single equation, reduced-form model, not a structural model. Although these reducedform models are used fairly frequently in the energy literature, they can offer limited information for policy decisions because such models ignore issues such as inter-fuel substitution, technical change, and changes in supply (Bhattacharyya, 2011).

Finally, I acknowledge that spatial econometric models may suffer from issues of identification (endogeneities within the explanatory variables) and a lack of theoretical foundation as pointed out by Partridge et al. (2012). But the same issues can be pointed out about reducedform models in the econometrics literature in general. The relationship between $\mathrm{CO}_{2}$ emissions and economic drivers is highly complicated, so studies often use decomposition analyses (with similar explanatory variables as this particular study) such as the Kaya identity found within IPCC reports (IPCC, 1996). Decomposition analyses are useful for analyzing this relationship for descriptive purposes, but it is merely an accounting identity not a rigorously defined statistical analysis. Therefore, I argue that spatial econometric models will continue to contribute to this larger literature as it helps to disentangle the complicated relationship between emissions and the economy. 


\section{CHAPTER 6: PROVINCE LEVEL CONVERGENCE OF CHINA CO2 EMISSION INTENSITY}

In this essay, I followed the work of Yu and Lee (2012) by adopting a spatial, dynamic panel data (SDPD) approach to analyze convergence. After controlling for spatial effects, we investigate how the estimated rate of convergence changes. Compared to previous studies, this study offers two unique contributions to the literature. First, I offer an analysis of the convergence of energy-related emission intensities at the province-level in China. It is difficult to compare total carbon dioxide emissions across provinces because of the variation in their size and economic activity, so I instead analyze province-level emission intensities. Emission intensity normalizes emissions across provinces to offer a more compatible apples-to-apples comparison. From a policy sense, an analysis of emission intensity offers a more equitable measure for negotiating multilateral agreements. Second, I use a novel spatial, dynamic panel data model which includes both the individual effects and the spatial effects. By including the individual effects, I potentially avoid the omitted variable bias in the cross-sectional regression, and by including the spatial effects, I potentially avoid the omitted variable bias in the non-spatial, dynamic panel data regression.

Based on the estimation results, I find evidence that $\mathrm{CO}_{2}$ emission intensities are converging across provinces in China. I also find that the rate of convergence is higher with the dynamic panel data model (conditional convergence) than with a cross-sectional regression model (absolute convergence). This result is consistent with the study of Islam (1995). The individual effects that are ignored in cross-sectional regressions potentially create omitted variable bias. The panel data framework arguably offers a more precise (efficient) rate of convergence. Finally, I find that province-level $\mathrm{CO} 2$ emission intensities are spatially correlated, and the rate of convergence, when controlling for spatial autocorrelation, is higher than with the non-spatial models. This result 
is consistent with the study of Yu and Lee (2012). According to past literature a significant factor in understanding economic growth convergence is through the persistent difference in levels of technology across regions (Krugman, 1987; Islam, 1995; Jones, 1997). Lesser differences in technology levels suggest that convergence would proceed at a faster rate. The results imply that technological spillovers, embodied in both the unobserved individual effects and the spatial autocorrelation coefficient, have a direct effect on the rate of convergence of carbon intensity among provinces.

\subsection{Regression Model}

\subsubsection{Cross Section Regression Model}

The traditional neoclassical cross-sectional regression model assumes that all regions or economies under consideration have the same steady state income path. In this particular case, it would imply that if provinces have similar technologies and environmental policies, then higher emission intensity provinces' emission should decrease faster than lower emission intensity provinces. The general cross-sectional regression model is given as follows

$$
\ln \left(y_{i, t+\tau}\right)=\alpha+\beta \ln \left(y_{i, t}\right)+\varepsilon_{i, t+\tau},
$$

where $y_{i, t}$ is the emission intensity for province $i$ at initial time point $t, y_{i, t+\tau}$ is the emission intensity for province $i$ at the end of time point, $t+\tau$, and $\tau$ is the time interval. That is, the regression observes the convergence of the emission intensity of the time period $[t, t+\tau]$. I assume that the rate of convergence, $\beta$, is defined by an exponential decay function as follows

$$
\beta=e^{-\tau \gamma},
$$


where an estimate of $\hat{\beta}$ within the interval $0<\beta<1$ implies that convergence to the steady state is direct and involves no oscillations. The parameter $\gamma$ is the implied rate of convergence, which can be calculated from the regression results as follows

$$
\gamma=-\ln (\hat{\beta}) / \tau
$$

The term "cross-sectional regression" is often confused because there is a province-level index, $i$, and a time interval index, $\tau$, that are specified in (6-2). Such a specification makes it appear as if this is a panel data approach. However, the subscripts are for notational purposes only. A time interval is specified because the model uses the natural log of province-level emission intensity in the last year of the interval against the natural log of province-level emission intensity in the initial year of the interval. As the interval increases, the effect of the initial condition on the average growth rate declines (Barro and Sala-i-Martin, 2004). Within a large longitudinal or panel data set, one could in principal look at several different intervals across the full sample. Such procedures are often used to omit any trending or cyclical behavior within the data that may affect the convergence estimates. An example is provided by Barro and Sala-i-Martin (2004), in which the authors examine the convergence of personal income across U.S. states for the period 19802000. The authors then estimate beta convergence across eleven ten-year-intervals over the entire sample. There is no concrete method for choosing the length of each interval - the selection, although arbitrary, depends on the full sample size and the frequency of observations (i.e., daily, monthly, quarterly, or annually).

As I mentioned above, it is important to investigate the spatial patterns that may indicate the spillover effects among regions. If I include the spatial lag of the dependent variable in the equation, then I derive the cross-sectional spatial autoregressive (SAR) model (Rey and Montouri, 1999) as follows 


$$
\ln \left(y_{i, t+\tau}\right)=\alpha+\rho \sum_{j=1}^{N} W_{i j} \ln \left(y_{i, t+\tau}\right)+\beta \ln \left(y_{i, t}\right)+\varepsilon_{i, t+\tau},
$$

where $\rho$ denotes the scalar, spatial autoregressive parameter on the dependent variable,

Furthermore, if I include both the contemporary spatial effects and the lagged spatial effects in the equation ( $\mathrm{Yu}$ and Lee, 2012), then I would derive the spatial cross section regression model

$$
\ln \left(y_{i, t+\tau}\right)=\alpha+\rho \sum_{j=1}^{N} W_{i j} \ln \left(y_{i, t+\tau}\right)+\beta \ln \left(y_{i, t}\right)+\lambda \sum_{j=1}^{N} W_{i j} \ln \left(y_{i, t}\right)+\varepsilon_{i, t+\tau},
$$

where $\lambda$ is spatial autocorrelation coefficient on the initial emission intensity levels.

Overall, since there are no controls on province-level heterogeneous fixed effects in the above cross-sectional regression and spatial regression models, the estimates are interpreted as absolute convergence.

\subsubsection{Dynamic Panel Data Model}

As Quah (1993) points out, the traditional cross-sectional approach does not reveal the dynamics of the growth processes. In response, Islam (1995) proposed a panel data approach to study growth convergence. The motivation for the panel data approach is to capture the differences across regions or countries. The unobserved differences such as preferences and technology are not easily measurable, so they can be treated as unobserved individual effects in the panel data regression framework (Hsiao, 2002). The general econometric specification of a dynamic panel data model is given as follows

$$
\ln \left(y_{i, t}\right)=\beta \ln \left(y_{i, t-1}\right)+\mu_{i}+\varepsilon_{i, t},
$$


where $\mu_{i}$ denotes the individual effect for each province. To avoid confusion between the crosssectional models in the previous subsection, I use the subscript $i$ to denote each region and $t$ to denote each time period. Note the contrast between $\tau$ in the previous subsection and $t$ in the current subsection. With the approach in this subsection, I examine beta convergence within a longitudinal or pooled data set. It should be noted that in principle one could examine the panel data within intervals as well.

Even though the dynamic panel data model could reveal the dynamic growth process, there are may be spillover effects from one region to the adjacent regions. For example, technological diffusion and environmental policies may follow a spatial pattern as regions may have different capacities to create or absorb new technologies and policies. Therefore, this modeling approach seeks to control for spatial autocorrelation within a dynamic panel data framework. By using the spatial dynamic panel data (SDPD) models with fixed effects, I can avoid not only the omitted variable bias in the cross sectional regression (where the individual effects are omitted), but also the omitted variable bias in the dynamic panel data regression (where the spatial effect is omitted).

Similar to the cross-sectional model, if I include the spatial lag of the dependent variable in the equation, then I would get the dynamic panel SAR model as follows

$$
\ln \left(y_{i, t}\right)=\rho \sum_{j=1}^{N} W_{i j} \ln \left(y_{i, t}\right)+\beta \ln \left(y_{i, t-1}\right)+\mu_{i}+\varepsilon_{i t}
$$

Further, if I include both the contemporary spatial effects and the lagged spatial effects in the equation, then I derive the spatial dynamic panel data model as follows

$$
\ln \left(y_{i, t}\right)=\rho \sum_{j=1}^{N} W_{i j} \ln \left(y_{i, t}\right)+\beta \ln \left(y_{i, t-1}\right)+\lambda \sum_{j=1}^{N} W_{i j} \ln \left(y_{i, t-1}\right)+\mu_{i}+\varepsilon_{i t} .
$$

While the cross sectional estimates might be better interpreted as rates of absolute convergence, those of the panel models can be interpreted as the rates of conditional convergence. 
Conditional convergence is interpreted as convergence after differences in the steady states across different regions have been controlled for; i.e., by controlling for the heterogeneous fixed effects $\mu_{i}$.

\subsection{Estimation Results}

In this study, I divide the entire sample into several shorter time intervals. As Islam (1995) argued, one can use a time span for just one year, which is technically feasible given that the underlying data set provides annual data. However, yearly time spans are generally too short to be appropriate for studying growth convergence. In other words, short-term disturbances may loom large in such brief time spans. Additionally, by considering the spatial effects, a shorter time span, such as one or two year span may be inappropriate because the spillover effects (such as technological spillovers) might take several years to propagate across regions. Hence, I choose five year time intervals as is done in Islam's (1995) use of the dynamic panel data approach and in accordance with China's "Five-Year Plans"; i.e., $\tau=5$. Therefore, I use the corresponding years for this analysis: 1990, 1995, 2000, 2005, and 2010. Following Yu and Lee (2012), I also estimate the model with four year intervals to check whether the results are robust to different time interval specifications.

\subsubsection{Empirical Results Using Cross Sections}

In this section, I estimate single cross-sectional regression model for the entire sample period, and estimate pooled cross-sectional regression models with five-year and four-year intervals. For the single cross-sectional regression model, I regress $\ln \left(y_{2010}\right)$ on $\ln \left(y_{1990}\right)$. For the 
five-year spans, I regress $\ln \left(y_{2010}\right)$ on $\ln \left(y_{2005}\right), \ln \left(y_{2005}\right)$ on $\ln \left(y_{2000}\right), \ln \left(y_{2000}\right)$ on $\ln \left(y_{1995}\right)$, and $\ln \left(y_{1995}\right)$ on $\ln \left(y_{1990}\right)$, and then construct the mean value of the regressions. I also present the parameter estimates for the four-year interval specification. The results of the cross sectional regression without spatial effects is presented in Table 6.1.

Table 6.1. Cross-Sectional Regression without Spatial Effects

\begin{tabular}{|c|c|c|c|c|c|}
\hline & Period & Constant & $\beta$ & $R^{2}$ & $\begin{array}{l}\text { Implied } \gamma \\
\left(\beta=e^{-\tau \gamma}\right)\end{array}$ \\
\hline $\begin{array}{c}\text { Single Cross } \\
\text { Sectional Regression } \\
\end{array}$ & $1990-2010$ & $\begin{array}{c}-0.6556 \\
(-1.6762) \\
\end{array}$ & $\begin{array}{c}0.5574 * * * \\
(3.4738) \\
\end{array}$ & 0.3012 & $\begin{array}{l}0.0292 \\
(\tau=20)\end{array}$ \\
\hline \multirow{5}{*}{$\begin{array}{l}\text { Pooled Regression } \\
\text { with } 5 \text { Year Intervals }\end{array}$} & 1990-1995 & $\begin{array}{l}-0.2594 \\
(-1.4281)\end{array}$ & $\begin{array}{l}0.8350 * * * \\
(11.2043)\end{array}$ & 0.8176 & \\
\hline & $1995-2000$ & $\begin{array}{l}-0.0663 \\
(-0.4208)\end{array}$ & $\begin{array}{l}0.7837 * * * \\
(8.9314)\end{array}$ & 0.7402 & \\
\hline & $2000-2005$ & $\begin{array}{l}-0.0911 \\
(-0.6071)\end{array}$ & $\begin{array}{l}0.9617 * * * \\
(8.7389)\end{array}$ & 0.7317 & \\
\hline & 2005-2010 & $\begin{array}{c}-0.4482 \\
(-4.2141)\end{array}$ & $\begin{array}{l}0.9753 * * * \\
(11.4824)\end{array}$ & 0.8248 & \\
\hline & $\begin{array}{c}\text { Joint } \\
\text { subperiods }\end{array}$ & $\begin{array}{c}-0.2162 \\
(-1.6675)\end{array}$ & $\begin{array}{c}0.8889 * * * \\
(10.0893)\end{array}$ & 0.7786 & $\begin{array}{c}0.0236 \\
(\tau=5)\end{array}$ \\
\hline \multirow{6}{*}{$\begin{array}{l}\text { Pooled Regression } \\
\text { with } 4 \text { Year Intervals }\end{array}$} & 1990-1994 & $\begin{array}{c}-0.3773^{*} \\
(-1.8758)\end{array}$ & $\begin{array}{c}0.9659 * * * \\
(11.7057)\end{array}$ & 0.8243 & \\
\hline & 1994-1998 & $\begin{array}{c}0.1381 \\
(0.9151)\end{array}$ & $\begin{array}{c}0.6886 * * * \\
(9.1389)\end{array}$ & 0.7400 & \\
\hline & $1998-2002$ & $\begin{array}{c}-0.0475 \\
(-0.3883)\end{array}$ & $\begin{array}{c}0.8615 * * * \\
(10.7684)\end{array}$ & 0.7986 & \\
\hline & 2002-2006 & $\begin{array}{r}-0.3486 * * \\
(-2.7464)\end{array}$ & $\begin{array}{l}1.1367 * * * \\
(11.5074)\end{array}$ & 0.8192 & \\
\hline & 2006-2010 & $\begin{array}{c}-0.2644 * * * * \\
(-2.8595)\end{array}$ & $\begin{array}{c}0.9096 * * * \\
(11.4108)\end{array}$ & 0.8167 & \\
\hline & $\begin{array}{c}\text { Joint } \\
\text { subperiods }\end{array}$ & $\begin{array}{c}-0.1800 \\
(-1.3910)\end{array}$ & $\begin{array}{c}0.9125 * * * \\
(10.9063)\end{array}$ & 0.7998 & $\begin{array}{c}0.0229 \\
(\tau=4)\end{array}$ \\
\hline
\end{tabular}

Note: The symbols $* * *, * *$ and $*$ denote a one, five and ten percent significance level, respectively. Numbers in the parentheses represent t-stat values. 
From Table 6.1, I find that the coefficients of the initial emission intensity are positive and significant for both the single cross-sectional regression and the pooled regressions, and the values are all between zero and one. These results imply that $\mathrm{CO}_{2}$ emission intensities are converging across provinces in China. For the entire sample period specification, the implied rate of convergence is 0.0292 for the single cross-sectional regression. The five-year and four-year interval specifications yield estimated rates of convergence of 0.0236 and 0.0229 , respectively. Therefore, the pooled cross sectional regression yield similar results to the single cross sectional results.

Table 6.2 reports the estimation of the cross-sectional SAR model. I find that the single cross-sectional regression yields a higher rate of convergence of 0.0345 for the entire sample period. By using five-year and four-year intervals, the estimated rates of convergence are 0.0167 and 0.0217 , respectively. Therefore, these regressions yield similar rates of convergence as the non-spatial models. 
Table 6.2. Cross-Sectional Regression with Contemporary Spatial Effects

\begin{tabular}{|c|c|c|c|c|c|c|}
\hline & Period & Constant & $\beta$ & $\rho$ & $R^{2}$ & $\begin{array}{l}\text { Implied } \gamma \\
\left(\beta=e^{-\tau \gamma}\right)\end{array}$ \\
\hline $\begin{array}{c}\text { Single Cross } \\
\text { Sectional Regression }\end{array}$ & $1990-2010$ & $\begin{array}{l}-0.6237 * \\
(-1.6595) \\
\end{array}$ & $\begin{array}{c}0.5001 * * * \\
(2.8826) \\
\end{array}$ & $\begin{array}{c}0.1470 \\
(0.6299) \\
\end{array}$ & 0.2915 & $\begin{array}{l}0.0345 \\
(\tau=20)\end{array}$ \\
\hline \multirow{5}{*}{$\begin{array}{l}\text { Pooled Regression } \\
\text { with } 5 \text { Year Intervals }\end{array}$} & 1990-1995 & $\begin{array}{c}-0.2596 \\
(-1.4658)\end{array}$ & $\begin{array}{l}0.8386 * * * \\
(6.9081)\end{array}$ & $\begin{array}{c}-0.0047 \\
(-0.0322)\end{array}$ & 0.8111 & \\
\hline & $1995-2000$ & $\begin{array}{l}-0.0222 \\
(-0.1392)\end{array}$ & $\begin{array}{l}0.8469 * * * \\
(7.0515)\end{array}$ & $\begin{array}{c}-0.1179 \\
(-0.7597)\end{array}$ & 0.7476 & \\
\hline & $2000-2005$ & $\begin{array}{l}-0.0212 \\
(-0.1241)\end{array}$ & $\begin{array}{l}1.0279 * * * \\
(8.3092)\end{array}$ & $\begin{array}{r}-0.1339 \\
(-0.8666)\end{array}$ & 0.7205 & \\
\hline & $2005-2010$ & $\begin{array}{c}-0.4598 * * * \\
(-4.0914)\end{array}$ & $\begin{array}{l}0.9656 * * * \\
(10.5532)\end{array}$ & $\begin{array}{r}0.0320 \\
(0.8111)\end{array}$ & 0.8188 & \\
\hline & $\begin{array}{c}\text { Joint } \\
\text { subperiods } \\
\end{array}$ & $\begin{array}{c}-0.1907 \\
(-1.4551) \\
\end{array}$ & $\begin{array}{c}0.9198 * * * \\
(8.2055) \\
\end{array}$ & $\begin{array}{l}-0.0561 \\
(0.2119) \\
\end{array}$ & 0.7745 & $\begin{array}{c}0.0167 \\
(\tau=5)\end{array}$ \\
\hline \multirow{6}{*}{$\begin{array}{l}\text { Pooled Regression } \\
\text { with } 4 \text { Year Intervals }\end{array}$} & $1990-1994$ & $\begin{array}{l}-0.3787 * \\
(-1.9481)\end{array}$ & $\begin{array}{c}0.9048 * * * \\
(6.6889)\end{array}$ & $\begin{array}{c}0.0759 \\
(0.5227)\end{array}$ & 0.8229 & \\
\hline & 1994-1998 & $\begin{array}{c}0.1002 \\
(0.6269)\end{array}$ & $\begin{array}{c}0.6229 * * * \\
(5.9696)\end{array}$ & $\begin{array}{c}0.1119 \\
(0.7647)\end{array}$ & 0.7432 & \\
\hline & $1998-2002$ & $\begin{array}{c}0.0733 \\
(0.5988)\end{array}$ & $\begin{array}{c}1.0024 * * * \\
(9.8712)\end{array}$ & $\begin{array}{l}-0.2659 * * \\
(-2.0530)\end{array}$ & 0.8265 & \\
\hline & $2002-2006$ & $\begin{array}{l}-0.3557 * * \\
(-2.5253)\end{array}$ & $\begin{array}{l}1.1304 * * * \\
(10.1898)\end{array}$ & $\begin{array}{c}0.0140 \\
(0.1074)\end{array}$ & 0.8197 & \\
\hline & 2006-2010 & $\begin{array}{l}-0.2467 * * \\
(-2.2923)\end{array}$ & $\begin{array}{l}0.9234 * * * \\
(10.6697)\end{array}$ & $\begin{array}{l}-0.0450 \\
(-0.3154)\end{array}$ & 0.8163 & \\
\hline & $\begin{array}{c}\text { Joint } \\
\text { subperiods }\end{array}$ & $\begin{array}{l}-0.1615 \\
(-1.1080)\end{array}$ & $\begin{array}{c}0.9168 * * * \\
(8.6778)\end{array}$ & $\begin{array}{l}-0.0204 \\
(-0.1947)\end{array}$ & 0.8057 & $\begin{array}{c}0.0217 \\
(\tau=4)\end{array}$ \\
\hline
\end{tabular}

Note: The symbols ***, ** and $*$ denote a one, five and ten percent significance level, respectively. Numbers in the parentheses represent t-stat values.

Table 6.3 presents the results which include both contemporary spatial effects and lagged spatial effects. I see that the estimated rates of convergence in this single cross-sectional regression is 0.0380 , and the estimated rates of convergence are 0.0185 and 0.0239 for the pooled cross sectional regressions with five and four year intervals. These regressions also yield similar rates of convergence with the non-spatial model and cross sectional SAR model. 
Table 6.3. Cross-Sectional Regression with Contemporary Spatial Effects and Lagged Spatial Effects

\begin{tabular}{|c|c|c|c|c|c|c|c|}
\hline & Period & Constant & $\beta$ & $\rho$ & $\lambda$ & $R^{2}$ & $\begin{array}{l}\text { Implied } \gamma \\
\left(\beta=e^{-\tau \gamma}\right)\end{array}$ \\
\hline $\begin{array}{c}\text { Single Cross } \\
\text { Sectional Regression }\end{array}$ & $1990-2010$ & $\begin{array}{l}-0.6219^{*} \\
(-1.6581)\end{array}$ & $\begin{array}{l}0.4673 * * \\
(2.4667)\end{array}$ & $\begin{array}{c}0.1380 \\
(0.5910)\end{array}$ & $\begin{array}{c}0.0350 \\
(0.5187)\end{array}$ & 0.2985 & $\begin{array}{l}0.0380 \\
(\tau=20)\end{array}$ \\
\hline \multirow{5}{*}{$\begin{array}{l}\text { Pooled Regression } \\
\text { with } 5 \text { Year Intervals }\end{array}$} & 1990-1995 & $\begin{array}{c}-0.2569 \\
(-1.4737)\end{array}$ & $\begin{array}{c}0.8159 * * * \\
(6.5032)\end{array}$ & $\begin{array}{l}-0.0139 \\
(-0.0954)\end{array}$ & $\begin{array}{c}0.0286 \\
(0.9117)\end{array}$ & 0.8093 & \\
\hline & $1995-2000$ & $\begin{array}{c}-0.0226 \\
(-0.1411)\end{array}$ & $\begin{array}{c}0.8471 * * * \\
(6.7522)\end{array}$ & $\begin{array}{c}-0.1149 \\
(-0.7356)\end{array}$ & $\begin{array}{c}-0.0018 \\
(-0.0384)\end{array}$ & 0.7379 & \\
\hline & $2000-2005$ & $\begin{array}{c}-0.0213 \\
(-0.1242)\end{array}$ & $\begin{array}{l}1.0299 * * * \\
(8.0261)\end{array}$ & $\begin{array}{c}-0.1319 \\
(-0.8272)\end{array}$ & $\begin{array}{c}-0.0042 \\
(-0.0583)\end{array}$ & 0.7103 & \\
\hline & $2005-2010$ & $\begin{array}{c}-0.4755^{* * *} \\
(-4.1993)\end{array}$ & $\begin{array}{r}0.9531 * * * \\
(10.2716)\end{array}$ & $\begin{array}{c}-0.0129 \\
(-0.0940)\end{array}$ & $\begin{array}{c}0.0553 \\
(0.8599)\end{array}$ & 0.8166 & \\
\hline & $\begin{array}{c}\text { Joint } \\
\text { subperiods }\end{array}$ & $\begin{array}{c}-0.1941 \\
(-1.4846)\end{array}$ & $\begin{array}{c}0.9115^{* * * *} \\
(7.8883)\end{array}$ & $\begin{array}{l}-0.0684 \\
(-0.4447)\end{array}$ & $\begin{array}{c}0.0195 \\
(0.4381)\end{array}$ & 0.7685 & $\begin{array}{c}0.0185 \\
(\tau=5)\end{array}$ \\
\hline \multirow{6}{*}{$\begin{array}{c}\text { Pooled Regression } \\
\text { with } 4 \text { Year Intervals }\end{array}$} & 1990-1994 & $\begin{array}{l}-0.3789 * \\
(-1.9480)\end{array}$ & $\begin{array}{c}0.9111 * * * \\
(6.6279)\end{array}$ & $\begin{array}{c}0.0719 \\
(0.4929)\end{array}$ & $\begin{array}{c}-0.0030 \\
(-0.0841)\end{array}$ & 0.8165 & \\
\hline & 1994-1998 & $\begin{array}{c}0.0968 \\
(0.6118)\end{array}$ & $\begin{array}{c}0.6092 * * * \\
(5.6640)\end{array}$ & $\begin{array}{c}0.1019 \\
(0.6916)\end{array}$ & $\begin{array}{c}0.0233 \\
(0.5844)\end{array}$ & 0.7365 & \\
\hline & 1998-2002 & $\begin{array}{c}0.0757 \\
(0.6279)\end{array}$ & $\begin{array}{c}0.9854 * * * \\
(9.4548)\end{array}$ & $\begin{array}{l}-0.2849 * * \\
(-2.2059)\end{array}$ & $\begin{array}{c}0.0318 \\
(0.7511)\end{array}$ & 0.8247 & \\
\hline & $2002-2006$ & $\begin{array}{c}-0.3572 * * \\
(-2.5345)\end{array}$ & $\begin{array}{c}1.1245 * * * \\
(9.7909)\end{array}$ & $\begin{array}{c}0.0049 \\
(0.0371)\end{array}$ & $\begin{array}{c}0.0152 \\
(0.2256)\end{array}$ & 0.8131 & \\
\hline & $2006-2010$ & $\begin{array}{c}-0.2532 * * \\
(-2.3333)\end{array}$ & $\begin{array}{r}0.9145 * * * \\
(10.1748)\end{array}$ & $\begin{array}{l}-0.0710 \\
(-0.4804)\end{array}$ & $\begin{array}{c}0.0336 \\
(0.4632)\end{array}$ & 0.8100 & \\
\hline & $\begin{array}{c}\text { Joint } \\
\text { subperiods }\end{array}$ & $\begin{array}{c}-0.1634 \\
(-1.1152)\end{array}$ & $\begin{array}{c}0.9089 * * * \\
(8.3424)\end{array}$ & $\begin{array}{c}-0.0354 \\
(-0.2929)\end{array}$ & $\begin{array}{c}0.0202 \\
(0.3880)\end{array}$ & 0.8000 & $\begin{array}{c}0.0239 \\
(\tau=4)\end{array}$ \\
\hline
\end{tabular}

Note: The symbols $* * *, * *$ and $*$ denote a one, five and ten percent significance level, respectively. Numbers in the parentheses represent t-stat values.

However, the spatial effects in Table 6.2 and Table 6.3 are not significant. This might be due to omitted individual or heterogeneous effects. In the framework of cross-sectional regression, it is not possible to take account of the unobservable or unmeasurable factors such as the preference and technology. This would leads the bias estimation results. So I extend the analysis to include the individual effects with the spatial dynamic panel data model in the following section and compare the previous results with the estimated rates of convergence from the spatial dynamic panel data model. 


\subsubsection{Empirical Results Using Dynamic Panel Data}

According to Barro and Sala-i-Martin (2004), one advantage of panel data over cross sectional data is that one does not need to hold constant the steady state growth level because it is implicitly estimated using fixed effects. One potential problem with panel data models is that one needs a sufficiently large amount of time series observations in order to overcome dynamic panel data bias (Nickell, 1981; Judson and Owen, 1999). Dynamic panel data bias occurs when a lagged dependent variable is specified on the right hand side of the regression and the panel does not contain enough time series observations. To help ensure that I are getting efficient estimates of the speed of convergence, I use the bias-corrected least squares dummy variable (LSDVC) model. Judson and Owen (1999) showed that the LSDVC model provided the least biased estimates of the coefficient on the lagged dependent variable. The results presented in this section are the biascorrected results.

The results of the dynamic panel data model without spatial effects are presented in Table 6.4. Here, I see that the estimated rate of convergence is 0.1787 for the five year spans, and is 0.1403 for the four year spans. They are larger than the cross sectional estimates of 0.0236 and 0.0229 in Table 6.1. Hence, after considering the individual effects, I have a higher rate of convergence.

Table 6.4. Dynamic Panel without Spatial Effects

\begin{tabular}{|c|c|c|c|}
\hline & $\beta$ & $R^{2}$ & $\begin{array}{c}\text { Implied } \gamma \\
\left(\beta=e^{-\tau \gamma}\right)\end{array}$ \\
\hline 5 Year Intervals & $\begin{array}{l}0.4092 * * \\
(17.1500)\end{array}$ & 0.8552 & $\begin{array}{c}0.1787 \\
(\tau=5)\end{array}$ \\
\hline 4 Year Intervals & $\begin{array}{l}0.5706^{* *} \\
(16.4400)\end{array}$ & 0.8971 & $\begin{array}{c}0.1403 \\
(\tau=4)\end{array}$ \\
\hline
\end{tabular}

Note: The symbols ***, ** and * denote a one, five and ten percent significance level, respectively. Numbers in the parentheses represent t-stat values. 
The results for the dynamic panel SAR model and the SDPD model are summarized in Table 6.5 and Table 6.6, respectively. I find that the spatial effects are positive and statistically significant in Table 6.5 and Table 6.6. This implies that province-level $\mathrm{CO}_{2}$ emission intensities are spatially correlated in China and suggest that I should consider the spatial correlation in the growth regressions; otherwise there might be omitted variable bias due to excluding the spatial effects.

Table 6.5. Dynamic Panel with Contemporary Spatial Effects

\begin{tabular}{ccccc}
\hline & $\beta$ & $\rho$ & $R^{2}$ & $\begin{array}{c}\text { Implied } \gamma \\
\left(\beta=e^{-\tau \gamma}\right)\end{array}$ \\
\hline 5 Year Intervals & $0.3959 * * *$ & $0.4570 * * *$ & 0.9037 & 0.1853 \\
& $(5.9401)$ & $(5.3752)$ & & $(\tau=5)$ \\
4 Year Intervals & $0.5081 * * *$ & $0.3799 * * *$ & 0.9155 & 0.1693 \\
& $(8.1268)$ & $(5.0551)$ & & $(\tau=4)$ \\
\hline
\end{tabular}

Note: The symbols $* * *, * *$ and $*$ denote a one, five and ten percent significance level, respectively. Numbers in the parentheses represent t-stat values.

Table 6.6. Dynamic Panel with Contemporary Spatial Effects and Lagged Spatial Effects

\begin{tabular}{cccccc}
\hline & $\beta$ & $\rho$ & $\lambda$ & $R^{2}$ & $\begin{array}{c}\text { Implied } \gamma \\
\left(\beta=e^{-\tau \gamma}\right)\end{array}$ \\
\hline 5 Year Intervals & $0.3847 * * *$ & $0.4450 * * *$ & 0.0217 & 0.9035 & 0.1911 \\
& $(3.6918)$ & $(4.4751)$ & $(0.1688)$ & & $(\tau=5)$ \\
4 Year Intervals & $0.4416 * * *$ & $0.3010^{* * *}$ & 0.1423 & 0.9153 & 0.2043 \\
& $(5.1105)$ & $(3.0026)$ & $(1.2042)$ & & $(\tau=4)$ \\
\hline
\end{tabular}

Note: The symbols $* * *, * *$ and $*$ denote a one, five and ten percent significance level, respectively. Numbers in the parentheses represent t-stat values.

Strangely, the results for the dynamic spatial panel data model provide statistically insignificant estimates on the parameter of the temporally and spatially lagged autocorrelation coefficient, $\lambda$, in Tables 6.3 and 6.6. Since I used four and five year intervals within the data (which may cause this lack of significance because I are filtering out economic cycles), I test the model by using the full data set (i.e., I used one year time intervals). I find similar results that $\lambda$ 
is still insignificant (results not provided), which implies the insignificance is not due to the interval specification.

A possible explanation for the lack of statistical significance of $\lambda$ is that each province implements short-run strategies to reduce emission intensity to comply with pressure from the national government. This is further reinforced by the significance of $\rho$, which is the parameter on the contemporaneous spatially lagged dependent variable. These parameters suggest perhaps that provinces are adopting short-run measures to ease emission intensity, which explains the evidence of spatial dependence found with the significance of contemporaneous spatially lagged variable. The lack of significance of $\lambda$ may suggest that individual provinces are adopting different medium-run strategies or policies to reduce emission intensity. If the medium run strategies are not uniform across provinces then I would not expect to see evidence of spatial spillovers in the temporally and spatially lagged dependent variable. This may also imply that provinces are endogenously enforcing rules to improve the environmental quality, which is found by Wang and Wheeler (1999). In this case, this suggests that medium-run, province-level policies to reduce carbon emission intensities are not uniform.

For the dynamic panel SAR model, the rate of convergence of the five year and four year spans are 0.1853 and 0.1693 , respectively, which are much larger than the cross sectional estimates of 0.0167 and 0.0217 in Table 6.2. For the SDPD model, the rate of convergence of the five year and four year spans are 0.1911 and 0.2043 , respectively, which are also larger than the cross sectional estimates of 0.0185 and 0.0239 in Table 6.3. Therefore, estimated rate of convergence is much higher with the dynamic panel data than the cross section regression. We can also interpret this as the rate of conditional convergence is higher than the absolute convergence. 
After considering the spatial effects, the rate of convergence of the dynamic panel SAR model and the SDPD model with five year intervals are 0.1853 and 0.1911 , which are larger than the rate of convergence of the non-spatial panel data model. We have the same result with the four year intervals as well. Therefore, the technological spillover reduces the persistent difference of the technology level among the provinces, thus leads a faster rate of convergence.

\subsection{Conclusions}

In this essay, I analyzed the provincial convergence of $\mathrm{CO}_{2}$ emission intensity in China. I proposed a spatial dynamic panel data approach that controls for both time and space - this differs from the conventional panel date convergence literature which does not control for spatial autocorrelation. By using a spatial dynamic panel data model, I potentially avoid omitted variable bias if the underlying data are characterized by spatial dependence.

The findings of the province-level convergence of $\mathrm{CO}_{2}$ emission intensity imply that the provinces with high emission intensity and provinces with low emission intensity are tending to converge to the same steady state equilibrium over time. In other words, the province-level disparity of $\mathrm{CO}_{2}$ emission intensity is gradually shrinking over time, and the differences in the technology is less persistent across provinces.

By controlling for the heterogeneous effects and spatial effects, I are potentially controlling for factors such as energy consumption, technology and the province's energy infrastructure. Improvements in these factors may have direct positive effects on the provinces' short-run emission intensity level. The higher rate of convergence with the individual effects and the spatial effects imply that the technological spillover has a direct effect on the rate of convergence and is also embodied in the unobserved individual effects. 
The statistically significant spatial autocorrelation suggests that, while provinces may be converging to a unique steady state equilibrium, they do not do so independently but rather tend to display movements similar to their regional neighbors. The results from the spatial dynamic panel data model suggest that own-province policies may have an effect on neighboring provinces and vice versa in the short run, but not necessarily in the medium run. The lack of statistical significance of spatial effects in the long run suggests that provinces are not adopting uniform policies to mitigate carbon dioxide emissions intensities.

The existence of convergence implies that China has started to transition towards less energy and carbon intensive growth. However, according to Yang et al. (2014), the forecasting results suggest that China's carbon intensity in 2020 will be only $32.9 \%$ below the 2005 level, which implies that China would be short of the 40\%-50\% Copenhagen target. Therefore, in order to meet the Copenhagen commitment, additional mitigation efforts will be needed to ensure compliance.

A potential limitation within this study is due to the relative short nature along the time dimension of this data set. The natural process of convergence can take several decades if not longer to play out. Unfortunately, the data have a limit time frame of availability. However, with its tremendous growth, the Chinese economy has also got significant technological advancements and policies to reduce each province's $\mathrm{CO}_{2}$ emission intensities. Given these rapid advancements the results are perhaps telling of an initial sign of convergence, which suggests that provinces may have an easier task of negotiating emission reductions in the future. As additional data comes available it will be important for future studies to examine this relationship in China. 


\section{CHAPTER 7: FORECASTING PROVINCE LEVEL $\mathrm{CO}_{2}$ EMISSIONS IN CHINA $^{8}$}

This essay compares forecasts of province-level carbon dioxide emissions against empirical reality using dynamic panel data models with and without spatial effects. The spatial dynamic panel data models are a promising means to examine the spatial and temporal distribution of $\mathrm{CO}_{2}$ emissions.

This study contributes to the literature by offering an assessment of how the spatial panel data models perform in forecasting against non-spatial panel data models in a root mean square error context. I compare the performance of several predictors for province-level $\mathrm{CO}_{2}$ emissions for one through five-year-ahead forecasts. Based on forecast performance, I find a spatio-temporal panel data model (that controls for fixed effects) outperforms the other models analyzed. This finding suggests the importance of considering not only spatial and temporal dependence but also the individual or heterogeneous characteristics within each province.

\subsection{Regression Models}

In this particular study, I apply three different spatial econometric models with individual intercept for each province (fixed effects models) and common intercept for all of them (pooled models). In brief, I analyzed the following models: spatial autoregressive (SAR), spatial error model (SEM), spatio-temporal panel data models (STPD), and non-spatial, ordinary least squares (OLS).

\footnotetext{
${ }^{8}$ This essay is based upon the paper: Zhao, X., Burnett, J.W., 2013. Forecasting Province-Level $\mathrm{CO}_{2} \mathrm{Emissions} \mathrm{in}$ China. Letters in Spatial and Resource Science.
} 


\subsubsection{Dynamic, Pooled Panel Data Models}

The dynamic, pooled panel data model imposes the homogeneity restriction on both the intercept and slope coefficients across all provinces. It assumes equal average growth rates in all provinces and allows us to take advantage of the panel dimension. The dynamic, pooled panel data model is given as follows

$$
\begin{aligned}
y_{i t} & =\alpha+\rho \sum_{j=1}^{N} W_{i j} y_{j t}+\beta y_{i, t-1}+\lambda \sum_{j=1}^{N} W_{i j} y_{j, t-1}+\phi_{i t} \\
\phi_{i t} & =\delta \sum_{j=1}^{N} W_{i j} \phi_{j t}+\varepsilon_{i t},
\end{aligned}
$$

where $y_{i t}$ denotes $\mathrm{CO}_{2}$ emissions for the cross-sectional unit $i$ at time $t$. The parameter $\alpha$ is the common intercept for all the provinces; $\beta$ is a scalar parameter on the temporally lagged dependent variable; $\rho$ denotes the scalar spatial autoregressive parameter on the dependent variable; $\lambda$ is the spatial autocorrelation coefficient on the temporally lagged dependent variable; and $\delta$ is the spatial autocorrelation coefficient on the error term.

It should be noted that this model follows closely to that of Angulo and Trívez (2010), who explicitly identify that the estimators are biased but consistent with $T$, the total number of observations. The bias stems from including the temporally lagged dependent variables (or dynamic terms) on the right hand side of the equation. Nickell (1981) demonstrated that using the standard within-group estimator (more on this below) for dynamic models, with fixed individual effects, generates biased or worse inconsistent estimates as the number of cross-sectional observations tends toward infinity and the number of time series observations remains fixed. This is sometimes referred to as dynamic panel data bias. Using Monte Carlo analysis, Judson and Owen (1999) found that dynamic panel data bias is sizeable, even for models in which $T=20$; however, this biasedness is reduced by having a sufficiently large number of time series observations within 
the panel, and the degree of bias is affected by the strength of temporal autocorrelation within the data.

This approach somewhat circumvents this problem of dynamic panel data bias. Because I are appealing to the validation strategy of forecast performance evaluation to assess the models, so I are less concerned about proper model specification, estimation, and fit of the within-sample data, which is an alternative validation strategy. In other words, if the bias is substantial then one would expect that it would be revealed through the forecast error performance of the particular model. Thus, in an indirect manner, forecast performance evaluation is an alternative approach to assess estimation bias. That is, forecast performance evaluation can be an alternative to Monte Carlo analysis which directly seeks to estimate the degree of bias.

The restriction of the parameters within Equation (7-1) defines the specific type of spatial panel data model used. The spatial autoregressive model (SAR) is obtained by restricting both $\lambda=0$ and $\delta=0$. This model exhibits spatial dependence within only the dependent variable. The spatial error model (SEM) is obtained by restricting both $\rho=0$ and $\lambda=0$. This model exhibits spatial dependence within only the error terms. The spatio-temporal panel data models (STPD) is obtained by restricting $\delta=0$. This model allows for spatial dependence within both the dependent variable and the temporal dependent variable. Finally, if all the parameters with the exception of $\beta$ are restricted, then the model reduces to the traditional pooled OLS model.

\subsubsection{Dynamic Panel Data Models with Fixed/Random Effects}

The dynamic panel data models could be treated with fixed effects or with random effects. The model is given as follows 


$$
\begin{aligned}
& y_{i t}=\alpha_{i}+\rho \sum_{j=1}^{N} W_{i j} y_{j t}+\beta y_{i, t-1}+\lambda \sum_{j=1}^{N} W_{i j} y_{j, t-1}+\phi_{i t} \\
& \phi_{i t}=\delta \sum_{j=1}^{N} W_{i j} \phi_{j t}+\varepsilon_{i t} .
\end{aligned}
$$

The only difference between the fixed effects panel data model and the random effects panel data model is the intercept. In the fixed effects model, $\alpha_{i}$ is introduced as a dummy variable for each spatial unit, while in the random effects model, $\alpha_{i}$ is treated as a random variable that is independently and identically distributed with zero mean and variance $\sigma_{\alpha}^{2}$.

\subsubsection{Dynamic Fixed Effects Panel Data Models}

The dynamic fixed effect panel data model allows for province-specific intercepts, in order to account for the heterogeneity among spatial units. I can also define the same three types of spatial models as above by restricting the parameters.

Performing out-of-sample forecasting is straightforward when assessing pooled panel data models, but it more challenging when fixed effects are included. Schmalensee et al. (1998) and Auffhammer and Steinhauser (2012) forecasted the out-of-sample by examining a variety of specifications. Elhorst (2012) circumvented direct estimation of the fixed effect terms by demeaning the variables to eliminate the fixed effects from the regression equation - this provides an easier method to forecast the models. The least squares dummy variable (LSDV) estimator can be obtained by transforming the data as deviations from mean as follows

$$
y_{i t} *=y_{i t}-\frac{1}{T} \sum_{t=1}^{T} y_{i t} \text {. }
$$


This transformation eliminates the individual fixed effects. This type of estimator is sometimes referred to simply as the "fixed effects estimator" or "within estimator" instead of LSDV depending on which literature one reads.

\subsubsection{Dynamic Random Effects Panel Data Models}

The dynamic random effect panel data model assumes that the random variables $\alpha_{i}$ and $\varepsilon_{i t}$ are independent of each other. I could define three types of spatial models with random effects as well.

For the within-sample data (first 15 years), I find that the fixed effects model is more appropriate than the random effects model by using the Hausman's specification test (result not provided). The explanation of the Hausman test could be reviewed in the book of Baltagi (2005). However, whether the random effects model is an appropriate specification for the out-sample data remains uncertain. So I would like to estimate the random effects panel data models as well. Similar as the fixed effects panel data models, Elhorst (2009) provided the direct estimation of the random effect terms by demeaning the variables. The variable estimators could be obtained by the following equation

$$
y_{i t} \cdot=y_{i t}-(1-\theta) \frac{1}{T} \sum_{t=1}^{T} y_{i t} .
$$

where $\theta$ denotes the weight attached to the cross-sectional component of the data, with $0 \leq \theta^{2}=\sigma^{2} /\left(T \sigma_{\alpha}^{2}+\sigma^{2}\right) \leq 1$. If $\theta=0$, this transformation simplifies to the demeaning procedure of equation (7-4) and hence the random effects model to the fixed effects model. 


\subsection{Forecast Performance of the Different Models}

The purpose of this section is to obtain and evaluate the $\mathrm{CO}_{2}$ emission forecast performance for the thirty provinces in China. Before forecasting, I first regress the models using the withinsample observations (the first fifteen years of data). I then use the parameter estimates from these regressions to forecast out against the out-of-sample observations (the last five years of data). I assume the spatial autocorrelation $(\rho, \lambda, \delta)$ is consistent with the within-sample data when I do the out-of-sample forecasting. In other words, I compare the forecasts against empirical reality (in a forecasting error context) to determine which model provides the most accurate predictions.

\subsubsection{Estimation Results of With-in-Sample}

Based upon the regressions and post-diagnostic testing, the results of the within-sample regressions imply that the SAR model is the most appropriate specification of the dynamic pooled panel data models; the SEM model is the most appropriate specification of the dynamic random effects panel data model; and the spatio-temporal model is the most appropriate specification of the dynamic fixed effects panel data model. The results of these models are provided in Table 7.1, Table 7.2, and Table 7.3, respectively. 
Table 7.1 Estimation Results of the Dynamic Pooled Panel Data Models

\begin{tabular}{lllll}
\hline Determinants & OLS & SAR & SEM & STPD \\
\hline Constant & $0.0653 * * *$ & $0.0626 * * *$ & $0.0647 * * *$ & $0.0590 * * *$ \\
& $(7.8092)$ & $(7.4237)$ & $(7.0589)$ & $(6.3437)$ \\
$\beta$ & $0.9708 * * *$ & $0.9631 * * *$ & $0.9692 * * *$ & $0.9634 * * *$ \\
& $(102.8268)$ & $(94.4650)$ & $(101.1678)$ & $(94.7002)$ \\
$\lambda$ & NA & NA & NA & -0.0562 \\
& & $0.0360 * *$ & & $(-0.8458)$ \\
$\rho$ & NA & $(1.9011)$ & NA & 0.0880 \\
$\delta$ & & NA & 0.0940 & $(1.3454)$ \\
& & & $(1.4380)$ & NA \\
\hline$\sigma^{2}$ & 0.030 & 0.030 & 0.030 & 0.030 \\
$R^{2}$ & 0.959 & 0.960 & 0.959 & 0.960 \\
Sample & 450 & 450 & 450 & 450 \\
Log Like & 150.813 & 152.617 & 151.918 & 153.030 \\
\hline
\end{tabular}

Note: The symbols $* * *, * *$ and $*$ denote a one, five and ten percent significance level, respectively. Numbers in the parentheses represent t-stat values.

From the results in Table 7.1, I find that the spatial autocorrelation parameter of $\rho$ in the SAR model is statistically significant, but the spatial autocorrelation parameter of $\delta$ in the SEM model and the parameters of $\rho$ and $\lambda$ in the STPD model are non-significant. The SAR model is suggested as a more appropriate specification than the non-spatial model as well as the other spatial models (SEM and STPD) for the within-sample pooled regression analysis.

I also perform the Lagrange Multiple (LM) tests to test the hypotheses whether the SAR model and SEM is prefer than the non-spatial model. The LM test results in Table 7.4 show the SAR model is statistically significant, but the SEM model is not. 
Table 7.2 Estimation Results of the Dynamic Fixed Effect Panel Data Models

\begin{tabular}{lllll}
\hline Determinants & FE & SAR & SEM & STPD \\
\hline$\beta$ & $0.8448^{* * *}$ & $0.6833 * * *$ & $0.7882 * * *$ & $0.6482^{* * *}$ \\
& $(31.4920)$ & $(20.4311)$ & $(25.4302)$ & $\begin{array}{l}(17.7397) \\
0.1818^{* *}\end{array}$ \\
& NA & NA & NA & $\begin{array}{l}(2.5189) \\
0\end{array}$ \\
$\rho$ & NA & $0.2830 * * *$ & NA & $0.1650^{* * *}$ \\
$\delta$ & NA & NA & $0.2340 * * *$ & $(2.6382)$ \\
\hline$\sigma^{2}$ & 0.028 & 0.026 & 0.028 & 0.026 \\
$R^{2}$ & 0.688 & 0.720 & 0.688 & 0.722 \\
Sample & 450 & 450 & 450 & 450 \\
Log Like & 169.818 & 195.605 & 174.723 & 199.215 \\
\hline
\end{tabular}

Note: The symbols $* * *, * *$ and $*$ denote a one, five and ten percent significance level, respectively. Numbers in the parentheses represent t-stat values.

From the results in Table 7.2, I found that the spatial autocorrelation parameter of $\rho$ in the SAR model, the parameter of $\delta$ in the SEM model, and the parameters of $\rho$ and $\lambda$ in the STPD model are statistically significant. These results suggest that spatial models are more appropriate specifications than the non-spatial models for the within-sample fixed effect regression analysis.

As an additional step, I perform Likelihood Ratio (LR) tests to test the hypotheses whether the STPD model can be simplified to the SAR or SEM model. According to the LR test result (7.221, $2 d f, p<0.01)$, the null hypothesis of the STPD model could be simplified to SAR model is rejected at a one percent significant level; the null hypothesis of the STPD model could be simplified to SEM model is also rejected at a one percent significant level based on the LR test result $(48.985,2 d f, p<0.01)$. These results imply that the SAR and SEM models are rejected in favor of STPD model. 
Table 7.3 Estimation Results of the Dynamic Random Effects Panel Data Models

\begin{tabular}{lllll}
\hline Determinants & RE & SAR & SEM & STPD \\
\hline$\beta$ & $0.9692 * * *$ & $0.8925 * * *$ & $0.9299 * * *$ & $0.9091 * * *$ \\
& $(106.6390)$ & $(48.6421)$ & $(68.1787)$ & $\begin{array}{l}(54.051007) \\
-0.0748\end{array}$ \\
$\lambda$ & NA & NA & NA & $(-1.1131)$ \\
$\rho$ & NA & $0.1099 * * *$ & NA & $0.1609 * *$ \\
& & $(3.8628)$ & & $(2.5473)$ \\
$\delta$ & NA & NA & $0.1533^{* *}$ & NA \\
\hline$\sigma^{2}$ & 0.026 & 0.029 & 0.030 & 0.029 \\
$R^{2}$ & 0.962 & 0.954 & 0.955 & 0.954 \\
Sample & 450 & 450 & 450 & 450 \\
teta & NA & $0.4741^{* * *}$ & $0.1042 * *$ & $0.5422 * * *$ \\
\hline
\end{tabular}

Note: The symbols $* * *, * *$ and $*$ denote a one, five and ten percent significance level, respectively. Numbers in the parentheses represent t-stat values.

From the results in Table 7.3, I found that the spatial autocorrelation parameter of $\rho$ in the SAR model, the parameter of $\delta$ in the SEM model, and the parameters of $\rho$ in the STPD model are statistically significant. Thus, spatial models are more appropriate specifications than the nonspatial models for the within-sample random effect regression analysis.

I also perform the Lagrange Multiple (LM) tests to test the hypotheses whether the SAR model and SEM is prefer than the non-spatial model. The LM test results in Table 7.4 show the SEM model is statistically significant, but the SAR model is not. 
Table 7.4 LM test results of the different dynamic panel data models

\begin{tabular}{lccc}
\hline \multicolumn{1}{c}{ Test } & Pooled Model & Fixed Effects Model & Random Effects Model \\
\hline LM Spatial Lag & $3.7128 *$ & $55.4144 * * *$ & 0.1962 \\
LM Spatial Error & 2.4677 & $10.0946 * * *$ & $7.5185^{* * *}$ \\
Robust Spatial Lag & $2.3841 *$ & $49.2731 * * *$ & 1.5507 \\
Robust Spatial Error & 1.1389 & $3.9532 * *$ & $8.8730 * * *$ \\
\hline Note: The symbols $* * * * *$ and $*$ denote a one five and ten percent sionificance level respectively.
\end{tabular}

\subsubsection{Forecasting Performance}

I compute the prediction (forecasts) for the $i^{t h}$ individual province at a future period $T+\tau$ for $\tau=1,2, \ldots, 5$. The forecasts are conducted by regressing the model on the entire initial withinsample (15 years) designation, and then forecasting over the entire out-of-sample period (n years) using the empirical observations of the independent variables within the out-of-sample period. This method provides a metric for evaluating the short- or medium-run predictive ability of the model. Prediction is evaluated by means of root mean square error (RMSE), which is defined as

$$
R M S E=\left\{\frac{1}{N} \sum_{t=1}^{T} \sum_{i=1}^{N}[F(t)-A(t)]^{2}\right\}^{1 / 2}
$$

where $T$ is the total periods and $N$ is the total number of provinces. The term $F(t)$ denotes the forecast value and $A(t)$ denotes the actual empirical observation. Since the errors in a RMSE test are squared before they are averaged, the RMSE gives a relatively higher weight to large errors so the RMSE arguably offers a more severe penalty for inaccurate forecasting errors. Note that the smaller the RMSE value, the smaller the forecast error, so lower values imply more accurate forecasts. 
The results of the forecast error performance, in the context of RMSE, of the dynamic pooled panel data model and dynamic fixed effect panel data model are presented in Table 7.5.

Table 7.5 Forecast Error Performance of the different dynamic panel data models

\begin{tabular}{|c|c|c|c|c|c|c|}
\hline & 1 year & 2 years & 3 years & 4 years & 5 years & Average \\
\hline \multicolumn{7}{|c|}{ Pooled Models } \\
\hline OLS & 0.1719 & 0.1754 & 0.1743 & 0.1754 & 0.1663 & 0.1727 \\
\hline SAR & 0.1715 & 0.1747 & 0.1743 & 0.1736 & 0.1656 & 0.1719 \\
\hline SEM & 0.1721 & 0.1755 & 0.1752 & 0.1756 & 0.1756 & 0.1748 \\
\hline STPD & 0.1782 & 0.1794 & 0.1762 & 0.1797 & 0.1797 & 0.1786 \\
\hline \multicolumn{7}{|c|}{ Fixed Effects Models } \\
\hline $\mathrm{FE}$ & 0.0000 & 0.1377 & 0.1545 & 0.1561 & 0.1488 & 0.1194 \\
\hline SAR & 0.0000 & 0.1311 & 0.1459 & 0.1442 & 0.1386 & 0.1120 \\
\hline SEM & 0.0000 & 0.1345 & 0.1504 & 0.1532 & 0.1457 & 0.1168 \\
\hline STPD & 0.0000 & 0.1268 & 0.1449 & 0.1418 & 0.1381 & 0.1103 \\
\hline \multicolumn{7}{|c|}{ Random Effects Models } \\
\hline $\mathrm{RE}$ & 0.1714 & 0.1697 & 0.1693 & 0.1646 & 0.1571 & 0.1664 \\
\hline SAR & 0.2028 & 0.1820 & 0.1790 & 0.1764 & 0.1710 & 0.1822 \\
\hline SEM & 0.1808 & 0.1718 & 0.1714 & 0.1670 & 0.1607 & 0.1703 \\
\hline STPD & 0.1901 & 0.1768 & 0.1749 & 0.1713 & 0.1657 & 0.1758 \\
\hline
\end{tabular}

Note: Numbers highlighted in Bold above indicate the smallest forecast errors in each group of estimators. Numbers highlighted in Bold and Italic above indicate the smallest forecast errors among all the esimators.

From this table, I can highlight four important results. First, in terms of the dynamic pooled panel data model, the SAR model outperforms the other spatial models (SEM and STPD) and the non-spatial model (OLS) in all years of forecasting. Second, in terms of the dynamic fixed effect panel data model, the STPD model outperforms the other spatial models (SAR and SEM) and the non-spatial model (FE) in all years of forecasting. These out-of-sample forecasting results are consistent with the within-sample estimations. Third, in terms of dynamic random effect panel data model, the non-spatial model (RE) outperforms the other spatial models (SAR, SEM and STPD), these out-of-sample forecasts are not consistent with the within-sample estimation. Finally, it is also very clear that the fixed effect models outperform their pooled model and random effect model counterparts, and the spatio-temporal panel data model with fixed effects outperforms all other models. 


\subsection{Conclusions}

The interest in spatial econometrics models has grown markedly in the past three decades, and there are more and more of these models in empirical applications (Auffhammer and Carson, 2008; Auffhammer and Steinhauser, 2012; Yu and Lee, 2012). Criticisms surrounding identification issues and a lack of appeal to theory have cast some doubt on these models. To further test the validity of spatial panel data models, I compared the forecasting performance of these models against empirical reality using root mean square error tests. The findings suggest that a dynamic, spatio-temporal panel data model with fixed effects outperforms all the other models analyzed. These findings imply that spatial panel data models performed better in forecasting ability than the non-spatial models, and the models that control for fixed effects perform better than models that do not control for such effects.

The findings within this study are important for two reasons. From a policy standpoint, it is important to predict the trending behavior of carbon dioxide emissions. Understanding the changing trends will help better equip policy makers to design effective climate change mitigation policies in China. From a statistical standpoint, it is important to continue to test spatial econometric models to see how they perform against non-spatial models. With advances in spatial panel data econometrics, this methodology can now be tested in terms of the model's forecasting ability. The results suggest that controlling for both time and space improves prediction. 


\section{CHAPTER 8: CONCLUSIONS}

This dissertation presents three essays that investigate China province-level carbon dioxide emissions by using both general and newly developed spatial econometric techniques. The three essays investigate the influential factors of energy-related carbon dioxide emission intensity, whether the province-level $\mathrm{CO}_{2}$ emission intensity is convergence, and how the spatial panel data models perform in forecasting against non-spatial panel data models for province-level carbon dioxide emissions in China, respectively. Positive, statistically significant, spatial autocorrelations of the $\mathrm{CO}_{2}$ emissions and $\mathrm{CO}_{2}$ emission intensities among the provinces are found in all the three essays, which implies that any policies implemented in one province will have spillover effects in neighboring provinces. The determination of such spillover is important for future mitigation policies adopted in China.

The first essay (Chapter 5) studies the influential factors of energy-related $\mathrm{CO}_{2}$ emission intensity in China. I argue that there is spatial dependence among these influential factors which cross provincial lines. Spatial dependence implies that policies adopted within one province will affect policies in neighboring provinces. Specifically, I estimate a model of $\mathrm{CO}_{2}$ emission intensity based upon per-capita GDP, energy prices, population density, energy consumption structure and transportation structure at province-level from 1990-2010. The results suggest that emission intensities are negatively affected by per-capita, province-level GDP and population density, positively affected by energy consumption structure and transportation structure, and are not affected by energy prices.

In the second essay (Chapter 6), I examine whether the province-level $\mathrm{CO}_{2}$ emission intensity is convergence in China. Convergence in energy intensity could imply that technological differences across regions diminish over time (Herrerias, 2012). This study seeks to determine 
interregional differences in technology tend to disappear or increase over time. If differences diminish naturally over time then policymakers may be less worried about a mitigation scheme. If the differences tend to perpetuate or grow over time (which implies a lack of diffusion of energyrelated technologies) then it may be too difficult to reach the country's mitigation targets. In this essay, I test for the convergence hypothesis among a panel of provinces in China by using a newly developed spatial, dynamic panel data model (SDPD). The results suggest that $\mathrm{CO}_{2}$ emission intensities are converging across provinces in China. The rate of convergence is higher with the dynamic panel data model (conditional convergence) than with a cross-sectional regression model (absolute convergence), and the rate of convergence, when controlling for spatial autocorrelation, is higher than with the non-spatial models. The results imply that technological spillovers, embodied in both the unobserved individual effects and the spatial autocorrelation coefficient, have a direct effect on the rate of convergence of carbon intensity among provinces.

In the last essay (Chapter 7), I provide an empirical analysis of how the spatial panel data models perform in forecasting against non-spatial panel data models for province-level carbon dioxide emissions in China. From a policy standpoint, understating how to predict emissions is important for designing climate change mitigation policies. From a statistical standpoint, it is important to test spatial econometrics models to see if they are a valid methodology to describe the underlying data. This study contributes to the literature by offering an assessment of how the spatial panel data models perform in forecasting against non-spatial panel data models in a root mean square error context. I compare the performance of several predictors for province-level $\mathrm{CO}_{2}$ emissions for one through five-year-ahead forecasts. The results of this essay suggest that the best model of forecasting province-level $\mathrm{CO}_{2}$ emissions is the spatio-temporal panel data model with controlling the fixed effects. The findings demonstrate the importance of considering not only 
spatial and temporal dependence but also the individual of heterogeneous characteristics within each province.

\subsection{Policy Implications}

The final goal of this study is to provide a basic reference for policy makers to set emission reduction targets and policy. Although China has started to transition towards less energy and carbon intensive growth, there is still no reason to be optimistic that China's future $\mathrm{CO}_{2}$ emissions will meet the international admissions, such as the Copenhagen commitment. Therefore, besides continuing to emphasize some implemented policies, additional mitigation efforts will also be needed to ensure compliance.

- Economic development depending on "green growth". China has achieved miraculous economic growth over the past 30 years to become the world's second largest singlecountry economy. The rapid economic growth definitely decreased the emission intensity. However, it is recognized that the next round of economic development should depend on achieving "green growth" that meets both economic goals as well as those for environmental sustainability.

- Population aggregation with energy efficiency. Population-dense provinces in China contribute less emissions per GDP than other areas of the country. That is because, the efficiency of energy consumption in service establishments is higher in densely populated provinces. Therefore, population density increasing should accompany with higher energy efficiency for reducing emission intensities.

- Clean energy technology. Coal consumption accounted for the highest rate of total energy consumption in China, and the power transfer efficiency of coal is relatively lower than the 
other energy sectors. However, price reforms will be needed to establish a sound market economy, and economic openness enables China to access cleaner technologies at lower costs, both of which help achieve economic growth with less adverse environmental impacts and lower emission intensity.

- Further fuel efficiency standards. The transportation sector has become the most-rapidly growth contributor to $\mathrm{CO}_{2}$ emissions in China. Urbanization and transportation systems have caused the environmental quality to decline. To obtain mitigation targets based on Copenhagen commitments, a combination of policies that address technological advancements and the transition to more fuel efficiency standards is necessary.

- Deregulate energy prices. Even though China has recently instituted market-oriented reforms so that prices of fossil fuels more accurately reflect the true market cost, government policies such as subsidies and price controls still artificially lower energy prices in order to stimulate economic growth. China should increase its use of marketbased price to regulate pollution behavior. This price deregulate instrument can achieve the same environmental target as the command-and-control approach but with lower costs.

- Information and technology sharing and exchange. The findings of spatial autocorrelation imply that the technology diffusion does exist among the provinces in China. Technology has a positive impact on resource conservation and pollution abatement, the technology diffusion provides incentives for local government to innovate and adopt better and cheaper environmental friendly technology. Therefore, China should promote technology policies that encourage cost-effective green innovations instead of prescribing specific technologies to be adopted by individual provinces. 


\subsection{Further Discussion}

This dissertation generally provides a framework of province-level $\mathrm{CO}_{2}$ emissions in China, including the influential factors, the convergence rate, and the forecasting performances. It still suffers from some limitations, which also provide the directions for future work.

\subsubsection{Data Size and Quality}

The data set that used in this dissertation only includes the data from 1990 to 2010, which is a relative short nature along the time dimension, so the analysis only observed the impact factors, convergence and prediction in the short run. The natural process of convergence can take several decades if not longer to play out. And the long-run forecasting performances could provide better suggestions. So, the direction of future work would be to collect more year's data as possible. As additional data comes available it will be important for future studies to examine the long-run convergence and long-run prediction, which will help better serve policy making in the context of climate change mitigation.

In this dissertation, the measure of carbon dioxide emissions is based upon the consumption of energy but not actual ambient carbon dioxide emissions, and only considered three main basic sector in China, so it may subject to mis-measurement. However, this is the only available information for calculating the province-level emissions in China. Therefore, the only way that I can improve is the calculation method. The future work would be to calculate the $\mathrm{CO}_{2}$ emissions based on the small categories of each sector. 


\subsubsection{Model simulations with different variables}

In this dissertation, I only considered five explanatory variables as the impact factor in the first essay because of the data limitation. However, a lot of factors such as the inter-fuel substitution, technical change, and the industry structures will indeed affect the emission intensity. Future studies for the first essay should be include more explanatory variables in the model. Moreover, I didn't include any explanatory variable in the second and third essay. So future studies should consider the convergence and the forecasting ability of spatial panel data models by incorporating explanatory variables in the models.

For spatial econometric estimation, a spatial weights matrix is required to express the geographic structure of economic interactions among the provinces during the time period. In this dissertation, I use the most common geographical contiguity weights matrix. The advantage of this contiguity weights matrix is that the 0,1 matrix elements are easily measured. However, this geographical contiguity weights matrix is of questionable validity for some of the studies. For instance, in this dissertation, it does not take into account the change of the energy transitions. Therefore, the future studies could consider to develop a formulation that is more attuned to the energy transition system. 


\section{REFERENCES}

Aldy, J.E., 2006. Per Capita Carbon Dioxide Emissions: Convergence or Divergence? Environmental \& Resource Economics 33, 533-555.

Angulo, A.M., Javier Trivez, F., 2010. The impact of spatial elements on the forecasting of Spanish labour series. Journal of Geographical System 12, 155-174.

Anselin, L., 1998. Spatial Econometrics: Methods and Models. Kluwer Academic Publishers, Dordrecht.

Anselin, L., 2001. A companion to Theoretical Econometrics. Blackwell Publisher Lte. Massachusetts.

Anselin, L., Gallo, J.L., Jayet, H., 2008. Spatial panel econometrics. Dordrecht, the Netherlands: Kluwer.

Arbia, G., Basile, R., Piras, G., 2005. Using Spatial Panel Date in Modelling Regional Growth and Convergence. Instituto di Studi e Analisi Economica Working Paper Number 55.

Auffhammer, M., Carson, R.T., 2008. Forecasting the path of China's CO2 emissions using province-level information. Journal of Environmental Economics and Management 55, 229-247.

Auffhammer, M., Steinhauser, R., 2007. The future trajectory of US CO2 emissions: The role of state vs. aggregate information. Journal of Regional Science 47, 47-61.

Auffhammer, M., Steinhauser, R., 2012. Forecasting the Path of Us CO2 Emissions Using StateLevel Information. Review of Economics and Statistics 94, 172-185.

Baltagi, B.H., 2005. Econometric analysis of panel data (3rd edition). Wiley, New York. 
Baltagi, B.H., Bresson, G., Pirotte, A., 2012. Forecasting with spatial panel data. Computational Statistics \& Data Analysis 56, 3381-3397.

Baltagi, B.H., Li, D., 2006. Prediction in the panel data model with spatial correlation: the case of liquor. Spatial Economic Analysis 1, 175-185.

Barro, R.J., Sala-i-Martin, 2004. Economic Growth: MIT Press.

Barro, R.J., Sala-i-Martin, X., 1991. Convergence Across States and Regions. Brookings Papers on Economic Activity, 107-182.

Barro, R.J., Sala-i-Martin, X., 1992. Convergence. Journal of Political Economy 100, 223-251.

Barro, R.J., Sala-i-Martin, X., 1995. Economic Growth. McGraw Hill, New York.

Bhattacharyya, S.C., 2011. Energy Economics: Concepts, Issues, Markets and Governance. Springer-Verlag.

Blasing, T., Broniak, C., Marland, G., 2004. Estimates of annual fossil-fuel CO2 emitted for each state in the U.S.A. and the District of Columbia for each year from 1960 through 2001. Carbon Dioxide Information Analysis Center.

Boden, T.A., G. Marland, and R.J. Andres. 2013. Global, Regional, and National Fossil-Fuel CO2 Emissions. Carbon Dioxided Information Analysis Center, Oak Ridge National Laboratory, U.S. Department of Energy, Oak Ridge, Tenn. U.S.A. doi 10.3334/CDIAC/00001_V2013.

BP, 2012. Statistical review of world energy 2012. British Petroleum.

Brueckner, J.K., 2003. Strategic interaction among governments: An overview of empirical studies. International Regional Science Reviews 26, 175-188. 
Burridge, P., 1981. Testing for a Common Factor in a Spatial Autoregression Model. Environment and Planning A 13, 795-800.

CESY, 2012. China Energy Statistical Yearbook. 1992-2012. National Bureau of Statistics of China.

Conley, T.G., Ligon, E., 2002. Economic distance and cross-country spillovers. Journal of Economic Growth 7, 157-187.

CSY, 1991-2011. China Statistical Yearbook. National Bureau of Statistics of China.

CSY, 2012a. China statistical yearbook. National Bureau of Statistics of China.

Duro, J.A., Alcantara, V., Padilla, E., 2010. International inequality in energy intensity levels and the role of production composition and energy efficiency: An analysis of OECD countries. Ecological Economics 69, 2468-2474.

Elhorst, J., 2012. Matlab software for spatial panels. International Regional Science Reviews 35, $1-17$.

Elhorst, J.P., 2009. In Fischer MM, Getis A (Eds.) Handbook of Applied Spatial Analysis. Springer: Berlin Heidelberg New York.

Elhorst, J.P., 2010. Dynamic panels with endogenous interaction effects when T is small. Regional Science and Urban Economics 40, 272-282.

Ezcurra, R., 2007. Distribution dynamics of energy intensities: A cross-country analysis. Energy Policy 35, 5254-5259. 
Ezcurra, R., Pascual, P., Rapun, M., 2007. The spatial distribution of income inequality in the European Union. Environment and Planning A 39, 869-890.

Fan, C.C., Casetti, E., 1994. THE SPATIAL AND TEMPORAL DYNAMICS OF UNITEDSTATES REGIONAL INCOME INEQUALITY, 1950-1989. Annals of Regional Science 28, 177-196.

Fan, Y., Liu, L.C., Wu, G., Tsai, H.T., Wei, Y.M., 2007. Changes in carbon intensity in China: Empirical findings from 1980-2003. Ecological Economics 62, 683-691.

Fan, Y., Liu, L.C., Wu, G., Wei, Y.M., 2006. Analyzing impact factors of CO2 emissions using the STIRPAT model. Environmental Impact Assessment 26, 377-395.

Fingleton, B., 2009. Prediction Using Panel Data Regression with Spatial Random Effects. International Regional Science Reviews 32, 195-220.

Freedman, D.A., 1991. Statistical-Models and Shoe Leather. Sociological Methodology 21, 291313.

Gezici, F., Hewings, G.J.D., 2007. Spatial analysis of regional inequalities in Turkey. European Planning Studies 15, 383-403.

Giacomini, R., Granger, C.W.J., 2004. Aggregation of space-time processes. Journal of Econometrics 118, 7-26.

Gonzalez, D., Martinez, M., 2012. Changes in CO2 emission intensities in the Mexican industry. Energy Policy 51, 149-163. 
Halicioglu, F., 2009. An econometric study of CO2 emissions, energy consumption, income and foreign trade in Turkey. Energy Policy 37, 1156-1164.

Hang, L.M., Tu, M.Z., 2007. The impacts of energy prices on energy intensity: Evidence from China. Energy Policy 35, 2978-2988.

Herrerias, M.J., Liu, G., 2013. Electricity intensity across Chinese provinces: New evidence on convergence and threshold effects. Energy Economics 36, 268-276.

Hsiao, C., 2002. Analysis of Panel Data: Cambridge University Press.

IEA, 2012. CO2 Emissions from Fuel Combustion, 2012 Edition. International Energy Agency.

IPCC, 1996. Revised 1996 IPCC guidelines for national greenhouse gas inventories: Workbook volume 2. Intergovernmental Panel on Climate Change, United Nations.

IPCC, 2013. CLIMATE CHANGE 2013: THE PHYSICAL SCIENCE BASIS. WORKING GROUP I CONTRIBUTION TO THE IPCC FIFTH ASSESSMENT REPORT Climate Change. Intergovernmental Panel on Climate Change, United Nations.

Islam, N., 1995. Growth Empirics: A Panel Data Approach. The Quarterly Journal of Economics $110,1127-1170$.

Islam, N., 2003. What have we learnt from the convergence debate? Journal of Economic Surveys 17, 309-362.

Itkonen, J.V.A., 2012. Problems estimating the carbon Kuznets curve. Energy 39, 274-280.

Jalil, A., Mahmud, S.F., 2009. Environment Kuznets curve for CO2 emissions: A cointegration analysis for China. Energy Policy 37, 5167-5172. 
Jones, C., 1997. On the evolution of the world income distribution. Journal of Economic Perspectives 11, 19-36.

Judson, R.A., Owen, A.L., 1999. Estimating dynamic panel data models: a guide for macroeconomists. Economic Letters 65, 9-15.

Kambara, T., 1992. The Energy Situation in China. China Quart, 608-636.

Kelejian, H.H., Prucha, I.R., 2007. The relative efficiencies of various predictors in spatial econometric models containing spatial lags. Regional Science and Urban Economics 37, 363-374.

Kelejian, H.H., Robinson, D.P., 2000. Returns to investment in navigation infrastructure: An equilibrium approach. Annals of Regional Science 34, 83-108.

Keller, W., 2004. International technology diffusion. Journal of Economic Literature 42, 752-782.

Kholodilin, K.A., Mense, A., 2012. Forecasting the prices and rents for flats in large German cities. Working Paper.

Kholodilin, K.A., Siliverstovs, B., Kooths, S., 2008. A Dynamic Panel Data Approach to the Forecasting of the GDP of German Lander. Spatial Economic Analysis 3, 195-207.

Krugman, P., 1987. The narrow moving band, the Dutch disease, and the competitive consequences of Mrs Thatcher. Journal of Development Economics 45, 1-28.

LeSage, J.P., Pace, P.K., 2009. Introduction to Spatial Econometric. CRC Press, Boca Raton.

Li, H.A., Mu, H.L., Zhang, M., Li, N., 2011. Analysis on influence factors of China's CO2 emissions based on Path-STIRPAT model. Energy Policy 39, 6906-6911. 
Liddle, B., 2010. Revisiting world energy intensity convergence for regional differences. Applied Energy 87, 3218-3225.

Lin, S.F., Zhao, D.T., Marinova, D., 2009. Analysis of the environmental impact of China based on STIRPAT model. Environmental Impact Assessment 29, 341-347.

Lopez-Rodriguez, J., 2008. Regional Convergence in the European Union: Results from a Panel Data Model. Economic Bulletin 18, 1-7.

Ma, C., Stern, D.I., 2008. China's changing energy intensity trend: A decomposition analysis. Energy Economics 30, 1037-1053.

Ma, D.C., Hu, S.Y., Zhu, B., Jin, Y., 2012. Carbon substance flow analysis and CO2 emission scenario analysis for China. Clean Technologies and Environmental Policy 14, 815-825.

Ma, H., Oxley, L., 2012. The emergence and evolution of regional convergence clusters in China's energy markets. Energy Economics 34, 82-94.

Mankiw, N.G., Romer, D., Weil, D.N., 1992. A Contribution to the Empirics of Economic Growth. Quarterly Journal of Economics 107, 407-437.

Manski, C.F., 1993. Identification of Endogenous Social Effects - the Reflection Problem. Review of Economic Studies 60, 531-542.

Markandya, A., Pedroso-Galinato, S., Streimikiene, D., 2006. Energy intensity in transition economies: Is there convergence towards the EU average? Energy Economics 28, 121-145.

Markusen, J.R., Morey, E.R., Olewiler, N., 1995. Competition in Regional Environmental Policies When Plant Locations Are Endogenous. Journal of Public Economics 56, 55-77. 
MOT, 2011. Energy conversion and emission mitigation of highway and waterway transportation, 2011-2015. Ministry of Transport of the People's Republic of China.

Nickell, S., 1981. Biases in Dynamic-Models with Fixed Effects. Econometrics 49, 1417-1426.

Ohtsuka, Y., Kakamu, K., 2013. Space-Time Model versus VAR Model: Forecasting Electricity demand in Japan. Journal of Forecasting 32, 75-85.

Partridge, M., Boarnet, M., Brakman, S., Ottaviano, G., 2012. Introduction: Whither spatial economics? Journal of Regional Sciences 52, 167-171.

Qi, S., Yun, B., Li, K., 2011. An International Comparative Analysis on China's Economic Growth and the Convergence in Energy Intensity Gap and Its Economic Mechanism. Chinese Journal of Population, Resources and Environment 9, 65-75.

Quah, D., 1993. Galtons Fallacy and Tests of the Convergence Hypothesis. Scandinavian Journal of Economics 95, 427-443.

Rey, S.J., Montouri, B.D., 1999. US regional income convergence: A spatial econometric perspective. Regional Studies 33, 143-156.

Rothman, D.S., 1998. Environmental Kuznets curves - real progress or passing the buck? A case for consumption-based approaches. Ecological Economics 25, 177-194.

Schanne, N., Wapler, R., Weyh, A., 2010. Regional unemployment forecasts with spatial interdependencies. International Journal of Forecasting 26, 908-926.

Schmalensee, R., Stoker, T.M., Judson, R.A., 1998. World carbon dioxide emissions: 1950-2050. Review of Economics and Statistics 80, 15-27. 
Solow, R.M., 1956. A Contribution to the Theory of Economic Growth. Quarterly Journal of Economics 70, 65-94.

Stern, D.I., Common, M.S., Barbier, E.B., 1996. Economic growth and environmental degradation: The environmental kuznets curve and sustainable development. World Development 24, $1151-1160$.

Swan, T.W., 1956. Economic Growth and Capital Accumulation. Economic Record 32, 334-361.

UN, 2012. Carbon dioxide emissions (CO2), thousand metric tones of CO2. United Nations.

USEIA, 2012. EIA Analysis Briefs: China. U.S. Department of Energy.

Wang, H., Wheeler, D., 1999. Endogenous Enforcement and Effectiveness of China's Pollution Levy System. World Bank, Washington D.C.

WB, 2012. $\mathrm{CO}_{2}$ emissions (metric tones per capita). World Bank.

Yang Y., Zhang J., Wang C., 2014. Is China on Track to Comply with Its 2020 Copenhagen Carbon Intensity Commitment? http://www.escholarship.org/uc/item/1r5251g8

Yu, H.Y., 2012. The influential factors of China's regional energy intensity and its spatial linkages: 1988-2007. Energy Policy 45, 583-593.

Yu, J.H., de Jong, R., Lee, L.F., 2008. Quasi-maximum likelihood estimators for spatial dynamic panel data with fixed effects when both $\mathrm{n}$ and $\mathrm{T}$ are large. Journal of Econometrics 146, $118-134$.

Yu, J.H., de Jong, R., Lee, L.F., 2012. Estimation for spatial dynamic panel data with fixed effects: The case of spatial cointegration. Journal of Econometrics 167, 16-37. 
Yu, J.H., Lee, L.F., 2010. Estimation of Unit Root Spatial Dynamic Panel Data Models. Econometric Theory 26, 1332-1362.

Yu, J.H., Lee, L.F., 2012. Convergence: A spatial dynamic panel data approach. Global Journal of Economics 1, 36.

Zhao, X., Burnett, J.W., 2013. Forecasting province-level CO2 emissions in China. Letters in Spatial and Resource Science.

Zhao, X., Burnett, J.W., Fletcher, J.J., 2014. Spatial Analysis of China Province-Level CO2 Emission Intensity. Renewable and Sustainable Energy Reviews 33, 1-10. 